\title{
A SubFamília Drilliinae (GASTROPOda TURridae) na Costa NorTe E NORDESTE DO BRASIL - TAXONOMIA E CONSIDERAÇÕES ECOLÓGICAS.
}

\author{
WLADIMIR SIQUEIRA DOS SANTOS \\ wladsan64@aol.com \\ DEUSINETE DE OLIVEIRA TENÓRIO \\ dot@truenet.com.br
}

Departamento de Oceanografia da UFPE

\begin{abstract}
RESUMO
Foram estudados com objetivo de identificação taxonômica e do substrato abrigador preferencial gastrópodes da família Turridae, Drilliinae Morrison, 1966 coletados da costa norte e nordeste do Brasil entre as coordenadas de $05^{\circ} 28^{\prime} 00^{\prime} \mathrm{N}$ e $08^{\circ} 21^{\prime} 05^{\prime}$ 'S, através de dragagens realizadas pelas expedições Oceanográficas: Geomar I, Norte e Nordeste I, Norte e Nordeste II, Norte e Nordeste IV (PAVASAS), Pesquisador IV, Pesca Norte I, Pernambuco, Itamaracá e Recife. Esses gastrópodes em geral apresentam a concha de pequenas dimensões, fusiformes e com ornamentação variada, o canal sifonal é incompleto, o sinus tem forma de U sobre a região do ombro e a fórmula radular é 1.1.1.1.1.1. A identificação Taxonômica levou em consideração os caracteres conquiológicos observados sob microscópio estereoscópico e a sistemática adotada foi baseada em Powell (1942), Abbott (1974) e Rios (1994). Foram identificados nove gêneros, 18 espécies, destacando-se como gêneros mais representativos: Clathrodrillia, Splendrillia, Leptadrillia e Cerodrillia. A relação entre número de espécimens, sedimento abrigador, revelou que os Drilliinae têm preferencia pelo substrato arenoso.
\end{abstract}

Palavras chave: Drillinae, Turridae, Costa Norte e Nordeste do Brasil

\section{Abstract \\ The Subfamily Drillinae (Gastropoda Turridae) in the North and Northeast Coast of Brazil - Taxoniomy and Ecologicals Considerations}

The main objective of this research was to study gatropods of the families Turridae, Drillinae Morrison 1966 in order to classify them taxonomically and identify their preferencial substrate. Samples were collected from the North and Northeast coast of Brazil between $05^{\circ} 28^{\prime} 0$ ' $\mathrm{N}$ and $08^{\circ} 21^{\prime} 5^{\prime}$ 'S. A rectangular dredge was used during the following oceanographic expeditions: Geomar I; Norte/Nordeste I; Norte/Nordeste II; Norte/Nordeste IV (PAVASAS); Pesquisador IV; Pesca Norte I; Pernambuco; Itamaracá and Recife. Generally, these gastropods have shells with small dimensions $(3-30 \mathrm{~mm})$ that are fusiform and show varied ornamentation. The siphonal canal is incomplete, the sinus has a U-shape on the shoulder area. The radular formule is 1.1.1.1.1.1. A stereomicroscope was used to observe shell characateristics. These were considered for taxonomical classification based on Powell (1942), Abbott (1974) and Rios (1994). Nine genus and 18 species were identified. The most representative genus were: Clathrodrillia, Splendrillia, Leptadrillia and Cerodrillia. The relationship between specimens and sediment has shown that members of the subfamily Drilliinae have preference for sandy substrates.

Key words: Drillinae, Turridae, North and Northeast Coast of Brazil 


\section{INTRODUÇÃO}

A subfamília Drilliinae Morrison, 1966 (Gastropoda - Turridae) apresenta conchas pequenas e de tamanho médio variando entre 3 e $30 \mathrm{~mm}$, delgadas, com espira elevada e canal sifonal truncado e sinus em forma de U sobre a região do ombro. O sistema radular é característico: 1.1.1.1.1.1 (dentes raquidianos vestigiais, laterais e um par marginais). A subfamília Clavinae Casey, 1904, tem como homônimo a subfamília Clavinae MacCrady, 1859 (Rios, 1994).

Esta subfamília corresponde a uma subdivisão da família Turridae. Os turrídeos são um complexo de formas variadas, muito bem sucedidos que ocupam grande diversidade de habitats marinhos, cobrindo a maioria das áreas geográficas, desde os trópicos a regiões polares e desde águas rasas até grandes profundidades oceânicas (Powell, 1966). As conchas geralmente são pequenas a médias e fusiformes, com espira elevada e canal sifonal reto, de fácil reconhecimento pela sutura ou sinus anal periférico. O opérculo é córneo, ovalado ou alongado com núcleo terminal, sendo ausente nas subfamílias Mangelinae e Daphnellinae. Apresentam ainda uma rádula toxoglossa, semelhante a um arpão conectada a uma glândula venenosa e se apresenta com 3 tipos distintos: a) primitivo, com dentes central, lateral e marginal; b) Rádula,com ausência de dente lateral e o dente central alargado; c) Condição toxoglossa, no qual somente o dente marginal, um em cada lado permanece.

A sistemática e classificação da subfamília Drilliinae como a dos turrídeos em geral é muito complexa em decorrência da morfologia da concha e da rádula,resultado da falta de genótipos necessários para um estudo mais criterioso da concha e de suas partes moles.Isto reflete a necessidade de dragagens a serem realizadas ao longo da costa,permitindo assim ampliar os estudos da malacofauna brasileira de águas profundas.

Registros fósseis de Drilliinae foram feitos por Magalhães \& Mezzalira (1953), os quais apresentam quatro espécies de Drillia do Mioceno Inferior do estado do Pará. O mesmo gênero com quatro espécies fósseis foi registrado por Maury (1924) na localidade Rio Pirabas em fósseis terciários do Brasil com descrição de novas formas cretáceas. Os gêneros Spirotropis Sara, 1878 e Drilliola Cossmann, 1903 são citados por Wenz (1944) sendo o primeiro para a Europa e América do Norte desde o Oligoceno, a origem recente é dúbia;o segundo para a América do Norte e Antilhas é originário do Eoceno ao Recente e são citadas as regiões do Atlântico, Índias Ocidentais e provavelmente Indopacífico.

Muitos autores têm apresentado listagens dos representantes da família Turridae com citações referentes a sua ampla distribuição geográfica e a dificuldade que têm para sua identificação, dentre os quais destacam-se: Pilsbry (1929); Carcelles (1944); Olsson (1958); Bayer (1971); Cernohorsky (1972); Ekdale (1974); Altena (1975); Castellanos (1979) e Abbott (1982).

A primeira citação da ocorrência de moluscos pertencentes a família Turridae Swainson, 1840 na costa brasileira foi feita por Watson (1886), sendo as espécies dragadas durante a Expedição Oceanográfica “Challenger” coligidas ao largo da costa do Estado de Pernambuco.

O estudo da fauna malacológica é mencionada por vários autores, entre estes Morretes (1949); Rios (1970, 1975, 1985 e 1994); Mello (1979 e 1981); Mello e Barros (1991); Barros (1994) e Santos e Tenório (1997).

Um estudo mais profundo dos Turridae torna-se necessário na costa brasileira em decorrência da falta de material bibliográfico que contenha informações precisas sobre a determinação das espécies.

O estudo da subfamília Drilliinae realizado aqui foi limitado apenas aos caracteres conquiológicos,como a forma e tipo de ornamentação,número de voltas da protoconcha e abertura da concha.

O estudo dos representantes da subfamília Drilliinae tem como principais objetivos: identificar taxonomicamente as espécies depositadas na coleção de moluscos do Departamento de

Tropical Oceanography, Recife: v. 30, n. 1, p. 59-90, 2002 
Oceanografia da Universidade Federal de Pernambuco, levando em consideração o material coligido da Costa Norte e Nordeste do Brasil e caracterizar a distribuição ecológica e geográfica correlacionando essa distribuição com o tipo de substrato.

\section{MATERIAL E MÉtodos}

O material conquiológico analisado foi obtido por dragagens efetuadas na plataforma continental do Norte e Nordeste do Brasil, entre as coordenadas de $05^{0} 28^{\prime} 0^{\prime}$ ' $\mathrm{N}$ e $08^{0} 21^{\prime}{ }^{\prime}$ ”'S pelo Navio Oceanográfico Almirante Saldanha da Marinha do Brasil e por barcos de pesca de pequeno porte. Os espécimens estiveram presentes em 81 estações,realizadas em nove comissões oceanográficas: GM I - Geomar I (1968); N/NE I - Norte Nordeste I (1967); N/NE II - Norte nordeste II (1968); N/NE IV - Norte Nordeste IV (PAVASAS) (1987); PESQ. IV - MA Pesquisador IV Maranhão (1973); PN I - Pesca Norte I (1968); PE - Pernambuco (1968 1969);ITA - Itamaracá (1969) e REC - Recife (1967).

As estações referentes a cada comissão estão representadas na tabela 1, contendo: coordenadas, profundidades e tipos de sedimento.

Desse material foram selecionados apenas os exemplares que apresentam as conchas intactas,sem partes moles. Este material foi analisado com auxílio de microscópio estereoscópio para observação dos caracteres conquiológicos (ornamentação, abertura da concha, protoconcha) usados na identificação taxonômica. Para a identificação específica foram consultados Powell (1942), Abbott (1974), Rios (1994), Merlano \& Hegedus (1997), tendo sido adotada à sistemática de Rios (1994).

Estudos sobre a distribuição ecológica e geográfica foram baseados nos dados obtidos nas estações de coleta e na bibliografia citada anteriormente.

Todo o material se encontra acondicionado em recipientes de vidro devidamente etiquetados, contendo o nome da espécie, estação e comissão oceanográfica.

Os espécimens foram fotografados e desenhados em câmara clara acoplada ao estereomicroscópio e medidos utilizando-se paquímetro.

A área estudada compreende parte da plataforma continental brasileira,desde o estado do Amapá $\left(05^{\circ} 28^{\prime} \mathrm{N}\right)$ até o Estado de Pernambuco $\left(08^{\circ} 21^{\prime} 5^{\prime} \mathrm{N}\right)$.

Ao norte, na região amazônica, a plataforma continental é ampla, alcançando 150 milhas. A partir daí, sua largura vai sofrendo um decréscimo em sentido leste, exatamente na região de Recife, com largura entre 18 a 20 milhas, sendo relativamente plana e terminando por um declive abrupto ocorrendo entre 60 e 80 metros (Kempf et al.,1970).

Ao largo do litoral dos Estados do Ceará e Rio Grande do Norte, existe um relevo submarino bem acidentado, relacionado a fenômenos vulcânicos, dando uma série de picos, dos quais Rocas e Fernando de Noronha são testemunhos visíveis (Kempf, op. cit).

As correntes marítimas existentes no litoral norte e nordeste do Brasil estão sujeitas à influência da corrente sul equatorial que se bifurca na parte setentrional do litoral leste. $\mathrm{O}$ ramo norte origina a corrente norte brasileira que se forma a $10^{\circ} 30^{\prime} \mathrm{S}$, enquanto o ramo sul dá origem à corrente do Brasil. (Castro \& Miranda, 1998).

Com exceção da região amazônica, as massas d'água se apresentam bastante homogêneas, caracterizadas pelas altas temperaturas e salinidades. (Kempf op. cit.).

A denominação dos principais tipos de fundos conhecidos são o resultado das pesquisas realizadas por Kempf (1970), são eles: lama, areia, algas calcárias e organogênico.

Na região Norte e Nordeste, exceto a região amazônica, a lama é representada por manchas isoladas, de pequena extensão, sob influência direta dos rios costeiros. Este fundo predomina na maior parte da região amazônica, a oeste do rio Pará. A fauna desse tipo de fundo é muito 
especializada; são encontrados principalmente, moluscos, poliquetas, crustáceos e, em menor quantidade, equinodermes.

Os fundos de areia são constituídos por uma areia quartzosa, variando desde grossa de dimensões irregulares até fina e compacta, cuja distribuição está em relação com o afastamento da costa. No litoral leste, a faixa de areia é reduzida, provavelmente em decorrência ao intenso desenvolvimento de algas calcárias a partir de 20 metros de profundidade; na costa Norte, o substrato arenoso é mais largo à oeste, alcançando sua extensão máxima na altura do Pará. Observase um maior desenvolvimento de invertebrados comuns a toda região nordestina, como exemplo, os moluscos. (Kempf op. cit.)

Os fundos de algas calcárias formados por Melobesiacea (Rodophyceae Corallinaceae), são característicos do Nordeste brasileiro, ocorrem em toda a região, com exceção da região amazônica Ocidental.

Muito semelhante ao anterior, o fundo organogênico é caracterizado pelo desaparecimento das algas vivas e o aumento da porcentagem de lama no sedimento. A fração grossa é constituída de fragmentos orgânicos diversos e dificilmente reconhecíveis.

\section{RESUlTADOS}

Levando-se em consideração o material analisado, a Subfamília Drilliinae Morrison, 1966 está representada na costa Norte e Nordeste brasileira pelos seguintes gêneros e espécies: Drillia Gray, 1838: D. interpleura Dall \& Simpson, 1901; Spirotropis Sara, 1878: S. lithocolleta (Watson, 1881); Drilliola Cosmann, 1903: D. comatotropis (Dall, 1881); Clathrodrillia Dall, 1918: C. gibbosa (Kiener, 1840), C. paria (Reeve, 1846), C. albicoma (Dall, 1889) e C. minor (Dautzenberg, 1900); Splendrillia Hedley, 1922: S. coccinata (Reeve, 1845), S. lissotropis (Dall, 1881), S. carolinae (Bartsch, 1934), S. woodring; (Bartsch, 1934) e S. tantula (Bartsch, 1934); Leptadrillia Woodring, 1928: L. cookei (E. A. Smith, 1888) e L. splendida Bartsch, 1934; Fenimorea Bartsch, 1934: F. halidorema Schwengel, 1940; Cerodrillia Bartsch \& Rehder, 1939: C. thea (Dall, 1883) e C. perryae Bartsch \& Rehder, 1939; e o gênero Neodrillia Barstch, 1943: N. cydia Bartsch, 1943.

As espécies mais freqüentes foram: Neodrillia cydia, Cerodrillia perryae e Clathrodrillia minor; dentre estas, a última apresentou o maior número de exemplares.

\section{CARACTERES GERAIS DA SUBFAMília DRILLIINAE}

Conchas pequenas,com comprimento entre três e $30 \mathrm{~mm}$,fusiformes,delgadas, espira elevada comum aos representantes da família Turridae nome derivado do latim "turris" ou torre, vulgarmente denominados de caramujo-torre. A coloração varia entre branco a diversas tonalidades de marrom; escultura dividida em espiral e axial. A espiral apresenta o ápice (espira embrionária) reto e obtuso, paucispiral (com poucas espiras) ou multiespiral (com muitas espiras), apresentando linhas e cordões subsuturais. Internamente as espiras se enrolam em um eixo denominado columela e externamente se unem através de uma sutura até o início da última e maior volta da concha.

A escultura axial está constituída de sulcos, elevações ou costelas axiais presentes em todo o comprimento da concha. Abertura da concha estreita, distinguindo-se um bordo externo (lábio externo), liso, pregueado com protuberâncias em algumas espécies e um bordo interno (lábio interno). Parte anterior da abertura da concha apresenta uma fenda anal típica das espécies de Turridae, homóloga quanto à função,à dos grupos filogeneticamente mais antigos (Pleurotomariidae e Fissurellidae). Região posterior da abertura em forma de canal denominado de canal sifonal mediano. Sinus em forma de U sobre a região do ombro. Sistema radular 1.1.1.1.1.1.(dentes

Tropical Oceanography, Recife: v. 30, n. 1, p. 59-90, 2002 
raquidianos vestigiais, laterais e um par marginal). Todos os representantes possuem uma glândula venenosa.

\section{Gênero Drillia Gray, 1838.}

Concha claviforme, espira elevada, volta do corpo incompleta, canal sifonal entalhado. Ornamentação de dobras axiais proeminentes e linhas espirais espaçadas. Sinus profundo, em forma de U. Entalhe stromboide evidente. Protoconcha cônica com 2,5 voltas. (Rios, 1994). Tipo: Drillia umbilicata Gray, 1838, Enae Bartsch, 1934, Douglassia Bartsch, 1934 (Rios, 1994).

Drillia interpleura Dall \& Simpson, 1901 - (Figura 1).

SINÔNIMO: Drillia (Clathrodrillia) interpleura Dall \& Simpson, 1901 (Abbott, 1974).

DIAGNOSE: concha pequena (7,5 x 3mm), fusiforme de cor marrom avermelhado, com uma varize arredondada forte perto de $1 / 3$ da volta dorsal da abertura. Protoconcha com duas voltas arredondadas e lisas. Ângulo da espira $20^{\circ}$.

COMENTÁRIOS: Material dragado a 43 metros de profundidade em fundo de lama.

MATERIAL EXAMINADO: GM.I 47 (2)

DISTRIBUIÇÃO GEOGRÁFICA: América Central e Brasil (Pará).

\section{Gênero Spirotropis Sara, 1878.}

Concha fusiforme, espira elevada, apresentando voltas fortemente carenadas, volta do corpo curta, canal sifonal reto e sem entalhe, abertura de formato piriforme. Sinus em forma de um U, pouco profundo. Opérculo em forma de folha, núcleo terminal. Protoconcha arredondada a globosa, sem corte, 1,5 a 2 voltas. Tipo: S. carinatum (Philippi, 1844).

Spirotropis lithocolleta (Watson, 1881) - (Figura 2)

DIAGNOSE: Concha pequena $(9 \times 3,5 \mathrm{~mm})$, branca com 6 voltas. Ângulo da espira $=22^{\circ}$; ornamentada com raios axiais oblíquos que não alcançam as suturas, (12 na volta do corpo),sem ornamentação espiral. Abertura 1/3 da largura da concha. Região columelar alaranjada. Opérculo um tanto fino e amplo.

COMENTÁRIOS: Material dragado a 88 metros de profundidade em substrato arenoso e biodetrítico.

MATERIAL EXAMINADO: GM.I 57 (1); GM.I 72(2); sald. N/NE.II 1892 (2); P.N. I Dg. 3 (1).

DISTRIBUIÇÃO GEOGRÁFICA: Flórida, Antilhas, Brasil (Amapá e Pará). Albardão, Rio Grande do Sul (Rios, 1994).

Gênero Drilliola Cosmann, 1903.

Concha claviforme, esbranquiçada, com a extremidade anterior truncada. Espira reta. Superfície com cordas espirais lisas. Sinus profundo em forma de V. Lábio externo fino. Canal anterior curto. Protoconcha com escultura axial. TIPO: D. cossmanni (Meyer, 1887). Sinônimo: Microdrillia Casey, 1903.

Drilliola comatotropis (Dall, 1881). - (Figura 3)

SINÔNIMO: Pleurotoma tiara Watson, 1881; Microdrillia comatotropis (Dall, 1881). (Rios, 1994). DIAGNOSE: Concha pequena, branca, com oito voltas. Ângulo da espira $=27^{\circ}$. Primeiras três voltas com 10 a 18 costelas axiais, o restante com três cordas espirais por volta, abertura estreita e curta.

Tropical Oceanography, Recife: v. 30, n. 1, p. 59-90, 2002 
COMENTÁRIOS: Material dragado a 56 metros de profundidade em substrato arenoso.

MATERIAL EXAMINADO: Sald. N/NE.II 1892 (2)

DISTRIBUIÇÃO GEOGRÁFICA: Flórida, Antilhas, Brasil (Pará) e Albardão, Rio Grande do Sul, Brasil (Rios, 1994).

\section{Gênero Clathrodrillia Dall, 1918.}

Concha de tamanho pequeno a mediano, fusiforme, espira elevada em forma de torre reta e margem anterior truncada. Lábio externo interior. Tipo: C. gibbosa Born (1778).

Clathrodrillia gibbosa (Kiener, 1840) - (Figura 4)

SINÔNIMO: Drillia (Clathrodrillia) gibbosa (Born, 1778) (Abbott, 1974).

DIAGNOSE: Concha média a grande $(16,1 \times$ x 5,5mm) fusiforme; lábio externo delgado, denticulado, limitado no canal sifonal até uma pequena calosidade; ornamentada com um cordão subsutural, seguido por um canal liso e numerosas costelas axiais cruzadas por numerosos cordões espirais; com uma grande variz no dorso da última volta; sulco anal profundo e projetado para o exterior; cor creme a marrom claro concentrado na última volta; abertura branca. Ângulo da espira $30^{\circ}$.

COMENTÁRIOS: Material dragado entre 17 a 106 metros de profundidade em fundos de areia, lama e organogênico.

MATERIAL EXAMINADO: G.M. I 22(1); Sald.N/NE.II 1912(1); pesq.IVMA44(1)eRec. 108(1). DISTRIBUIÇÃO GEOGRÁFICA: Venezuela; Suriname e Brasil (Amapá, Pará, Maranhão e Pernambuco)(Rios,1994).

Clathrodrillia paria (Reeve, 1846) - (Figura 5).

DIAGNOSE: Concha pequena $(7,5 \times 3 \mathrm{~mm})$, branca, com seis voltas. Ângulo da espira $=30^{\circ}$ escultura de 12 a 13 raios axiais e numerosas linhas espirais.

COMENTÁRIOS: Material dragado entre 43 e 77 metros de profundidade em fundos de areia e lama.

MATERIAL EXAMINADO: GM.I 47 (2); GM.I 57 (3)

DISTRIBUIÇÃO GEOGRÁFICA: Antilhas e Brasil (Amapá; Pará; Maranhão e Espírito Santo) (Rios,1994).

Clathrodrillia albicoma (Dall, 1889) - (Figura 6).

SINÔNIMO: Drillia albicoma (Dall, 1889) (Abbott, 1974).

DIAGNOSE: Concha sólida (22 x 9mm), branca, com nove voltas ligeiramente convexas. Ângulo de espira $=22^{\circ}$. Protoconcha polida de 1,5voltas. Escultura de raios axiais oblíquos bem desenvolvidos (sutura a sutura), aproximadamente 14 na volta do corpo, e finas linhas espirais que não atravessam a ornamentação longitudinal. Abertura mais do que 1/3 da largura da concha. Sinus amplo e profundo, refletido dorsalmente.

COMENTÁRIOS: exemplares dragados entre 13 e 116 metros de profundidade em fundos de areia e lama.

MATERIAL EXAMINADO: GM.I 46 (3); GM.I 54 (7); GM.I arrasto (2); sald. III DG. 23 (1); P.N. I Dg 2 (1).

DISTRIBUIÇÃO GEOGRÁFICA: Golfo do México, Antilhas e Brasil (Pará e Piauí; Cabo Frio, Rio de Janeiro) (Rios,1994).

Clathrodrillia minor (Dautzenberg, 1900) - (Figura 7). 
DIAGNOSE: Concha pequena (8 x 3mm), branca, com 8 voltas. Semelhante às espécies anteriores, porém fusiforme-conoidal, tendo 12 raios axiais oblíquos; sem canal subsutural.

COMENTÁRIOS: Material dragado entre 0,35 e 88 metros de profundidade em fundos de areia, algas calcárias, lama, organogênico e detrítico.

MATERIAL EXAMINADO: GM.I 08 (2); GM.I 29 (1); GM.I 41 (2); GM.I 42 (2); GM.I 47 (4); GM.I 57 (3); GM.I 60 (3); Sald. N/NE.I 1657 (2) Sald. N/NE.I 1719-A (6); Sald. N/NE.I 1738-A (4); Sald. N/NE.I 1739-A (1); Sald. N/NE.I 1754 (1); Sald. N/NE.I 1767 (1); Sald. N/NE.I 1773-A (4); Sald. N/NE.I 1787 (6); Sald. N/NE.I 1813 (1); Sald. N/NE.I 1817-A (3); Sald. N/NE.II 1857 (3); Sald. N/NE.II 1872 (1); Sald. N/NE.II 1892 (9); Sald. N/NE.II 1906 (4); Sald. N/NE.II 1910 (17); PNI Drag. 3 (1); ITA. 35 (1); REC. 143 (1).

DISTRIBUIÇÃO GEOGRÁFICA: costa Meridional do Caribe, Norte da América do Sul, entre o Golfo de Salamanca (Colômbia) e o Norte do Brasil (Pará).

\section{Gênero Splendrillia Hedley, 1922}

Concha alta espiralada, base truncada, escultura com sulcos axiais proeminentes terminando na parte saliente. Esculturas somente axiais. Pregas fortemente desenvolvidas próximas à sutura. Sinus na parte saliente do declive, suave a profundo, ocasionalmente subtubular. Canal sifonal curto. Opérculo em forma de folha, núcleo terminal. Protoconcha com poucas espiras (paucispiral), ligeiramente arredondadas e lisas com duas voltas. Tipo: S. woodsi Beddome, 1883.

\section{Subgênero Syntomodrillia Woodring, 1928}

Concha alongada, ornamentada com amplas costelas arredondadas que se estendem entre as suturas e estrias espirais microscópicas nos espaços intercostais; canal sifonal e abertura curtos; uma varize proeminente atrás do lábio; seio anal amplo; protoconcha de 2 a 3 giros lisos. Tipo: $S$. lissotropis Dall, 1881.

Splendrillia coccinata (Reeve, 1845) (Figura 8).

SINÔNIMO:Cerodrillia coccinata (Reeve, 1845); Drillia coccinata (Reeve, 1845).(Merlando \& Hegedus, 1994).

DIAGNOSE: Concha alcançando $12 \mathrm{~mm}$ de comprimento, de cor rosa com seis voltas. Ângulo da espira $=30^{\circ}$. Volta do corpo com 8 a 10 raios axiais lisos e bem marcados.

COMENTÁRIOS: Material dragado entre 19 a 54 metros de profundidade em fundos de areia, algas calcárias e lama.

MATERIAL EXAMINADO: Sald. N/NE.I 1807 (2); PE. 34-A (1).

DISTRIBUIÇÃO GEOGRÁFICA: Antilhas e Brasil (Amapá; Pará; Maranhão; Pernambuco e Bahia).

Splendrillia lissotropis (Dall, 1881) - (Figura 9).

SINÔNIMO: Drillia lissotropis (Dall, 1889) (Bartsch, 1934).

DIAGNOSE: Concha pequena fusiforme, branca, com cinco voltas. Ângulo da espira $=27^{\circ}$. Protoconcha obtusa, brilhante e lisa. Escultura de ombros axiais radiais (11 na volta do corpo) anteriormente tornam-se obsoletos, costelas espirais fracas e entalhe bem marcado.

COMENTÁRIOS: Material dragado a 74 metros de profundidade em fundo de algas calcárias.

MATERIAL EXAMINADO: PE. 16-A (1).

DISTRIBUIÇÃO GEOGRÁFICA: Golfo do México; Antilhas e Brasil (Pernambuco e Rio de Janeiro). 
Splendrillia carolinae (Bartsch, 1934) - (Figura 10).

DIAGNOSE: Concha medindo (6 x 2mm), de cor rosa, cônica e alongada, com 6 voltas. Ângulo da espira $=30^{\circ}$. Escultura de raios axiais oblíquos bem desenvolvidos (aproximadamente 16 na volta do corpo). Ausência da escultura espiral. Base com sete linhas espirais. Parede cercada com um grande calo.

COMENTÁRIOS: Material dragado a 13 metros de profundidade em substrato arenoso.

MATERIAL EXAMINADO: GM.I 41 (4);

DISTRIBUIÇÃO GEOGRÁFICA: Antilhas e Brasil (Pará e Rio Grande do Sul).

Splendrillia woodringi (Bartsch, 1934) - (Figura 11).

SINÔNIMO: Syntomodrillia lissotropis, Woodring, 1928; Syntomodrillia Woodring Bartsch, 1934 (Bartsch, 1934)

DIAGNOSE: Concha pequena (13 x 4,5mm), fusiforme, branca amarelada; protoconcha de 2,5 giros arredondados; primeiros giros da teleoconcha com costelas axiais nodulosas, as quais se alargam nos giros subseqüentes e terminam sobre a base da columela (12 - 16 no último giro); espaços intercostais com estrias microscópicas restritas a metade anterior dos últimos 2-3 giros; base com 8-10 cordões espirais.

COMENTÁRIOS: Material dragado entre as profundidades de 24 a 78 metros em fundos arenolamosos e biodetríticos.

MATERIAL EXAMINADO: Sald. N/NE.I 1739-A (1); Sald. N/NE.II 1906 (1); Sald. N/NE.II 1910 (3); Pesq.IV MA. 53-B (2); Rec. 1071; Sald. N/NE.IV DG. 5 (1)

DISTRIBUIÇÃO GEOGRÁFICA: Flórida, Antilhas, Colômbia e Brasil (Amapá, Pará, Maranhão e Pernambuco).

Splendrillia tantula (Bartsch, 1934) - (Figura 12).

SINÔNIMO: Syntomodrillia tantula (Bartsch, 1934).

DIAGNOSE: Concha medindo (7 x 3mm), branca, similar a $S$. woodringi, porém mais forte e com menos cordas espirais na columela e mais delgada na protoconcha.

COMENTÁRIOS: Material dragado entre as profundidades de 23 a 35 metros em fundos de areia, algas calcárias e lama.

MATERIAL EXAMINADO: G.M. I 21(1); G.M. I 34(2); Sald. N/NE.I 1763(3); Sald. N-NE II 1855(2); Sald. N-NE II 1860(2); Sald. N-NE II 1889(1);

DISTRIBUIÇÃO GEOGRÁFICA: Antilhas e Brasil (Amapá; Pará; Maranhão; Ceará e Rio Grande do Norte).

\section{Gênero Leptadrillia Woodring, 1928.}

Concha fusiforme alongada e estreita, de giros convexos; espira alta; canal sifonal estreito e entalhado; costelas axiais fortes, estendidas entre a sutura; ornamentação espiral ausente ou restrita a base. Sinus largo e superficial. Protoconcha pouco forte de dois giros lisos. Tipo: L.parkeri Gabb, 1873.

Leptadrillia cookei (E. A. Smith, 1888) - (Figura 13)

DIAGNOSE: Concha pequena $(9,2 \times 3,5 \mathrm{~mm})$, branca, brilhante, com cinco voltas. Escultura de raios axiais bem desenvolvidos (12 em volta do corpo). Uma forte varize atrás do lábio externo. Columela ligeiramente torcida.

COMENTÁRIOS: Material dragado entre 43 e 80 metros de profundidade em fundos de areia, algas calcárias e lama. 
MATERIAL EXAMINADO: GM.I 21(2); GM.I 22(1); GM.I 33(1); GM.I 34(1); GM.I 42(1); GM.I 47(1); Sald. N/NE.I 1755(2);

DISTRIBUIÇÃO GEOGRÁFICA: Antilhas e Brasil (Amapá, Pará e Maranhão).

Leptadrillia splendida Bartsch, 1934 - (Figura 14).

DIAGNOSE: Concha pequena $(11 \mathrm{x} 4 \mathrm{~mm})$, brilhante, com seis voltas. Ângulo da espira $=28^{\circ}$. Escultura de fortes raios axiais (12 em volta do corpo). Uma varize muito forte atrás de lábio externo. Lábio interno comprimido para a columela como um calo forte. Cor branca a rosa claro.

COMENTÁRIOS: Exemplares dragados entre 44 e 63 metros de profundidade em fundos de areia, algas calcárias, lama e organogênico.

MATERIAL EXAMINADO: Sald. N/NE.I 1657(1); Sald. N/NE.I 1693(1); Sald. N.NE.I 1751(1); Sald. N/NE.I 1767(1); Sald. N/NE.I 1807-A (1).

DISTRIBUIÇÃO GEOGRÁFICA: Antilhas, Colômbia e Brasil (Amapá, Pará e Maranhão).

\section{Gênero Fenimorea Bartsch, 1934.}

Conchas em forma de clava, espira elevada, volta do corpo truncada a um canal sifonal muito curto. Protoconcha grossa, 1 e 2 voltas arredondadas lisas. Ornamentação de numerosas pregas axiais e espirais. Sinus em forma de U, profundo, subtubular. Fraco entalhe estrombóide. Tendência a formar uma varize arredondada atrás do lábio externo. Tipo: F. janetae Bartsch, 1934.

Fenimorea halidorema Schwengel, 1940 - (Figura 15).

DIAGNOSE: Concha pequena, fusiforme, com sete voltas. Ângulo da espira $=30^{\circ}$. Fundo creme com uma banda espiral púrpura-avermelhada no meio da volta. Ornamentação de raios axiais arredondados e linhas espirais microscópicas. Abertura aproximadamente 1/3 da largura da concha.

COMENTÁRIOS: Exemplares dragados entre 22 e 116 metros de profundidade em fundos de algas calcárias, lama e organogênico.

MATERIAL EXAMINADO: PN.I Dg. 2 (1); PE 08 (4); PE 34-A (1); PE 36 (2); PE 36-A (1); REC.III (1).

DISTRIBUIÇÃO GEOGRÁFICA: Flórida, Jamaica, Brasil (Amapá a Bahia; Fernando de Noronha e Pernambuco).

Gênero Cerodrillia Bartsch \& Rehder, 1939.

Concha alongada, fusiforme, branco, opaca, espira alta, voltas fracamente angulares, volta do corpo ovalada, canal sifonal estreito; ornamentada com costelas axiais proeminentes e linhas espirais microscópicas. Protoconcha de duas voltas arredondadas lisas. Ligeiramente carenadas axialmente. Lirações espirais muito finas sinus em forma de U. Rádula protolípica. Tipo: C. clappi Bartsch \& Rehder, 1939

Cerodrillia thea (Dall, 1883) - (Figura 16)

SINÔNIMO: C. carminura Dall, 1889 (Rios, 1994).

DIAGNOSE: Concha pequena (12 x 4,5mm), similar a C. Perryae, porém mais robusta e alongada, com costelas mais curtas e amplas. Ângulo da espira $=30^{\circ}$. Abertura mais ampla, seio anal bem desenvolvido; coloração marrom oliva, com as cristas das costelas lisas.

COMENTÁRIOS: coletados entre 19 e 28 metros de profundidade em fundos de algas calcárias.

MATERIAL EXAMINADO: Sald. N/NE.I 1730(1); REC. 38(1); REC.142(1).

DISTRIBUIÇÃO GEOGRÁFICA: Flórida e Brasil (Piauí e Pernambuco). 
Cerodrillia perryae Bartsch \& Rehder, 1939. - (Figura 17)

DIAGNOSE: Concha pequena, alongada e turriforme $(13 \times 5,5 \mathrm{~mm})$, com seis voltas. Ângulo da espira $=30^{\circ}$. Volta do corpo com 8-9 raios axiais espaçados, estrias espirais quase imperceptíveis, exceto na base, protoconcha branca, lisa, de dois giros; cor marrom alaranjado a rosa pálido, às vezes com uma banda marrom dourada na periferia.

COMENTÁRIOS: Material dragado entre 5,6 e 146 metros de profundidade em fundos de areia, algas calcárias, lama, organogênico, Halimeda e detrítico.

MATERAL EXAMINADO: GM.I 08 (5); GM.I 21 (6); GM.I 34 (4); GM.I 47 (2); GM.I 57 (4); GM.I 60 (2); Sald. N/NE.I 1668-A (4); Sald. N/NE.I 1684-B (1); Sald. N/NE.I 1738-A (1); Sald. N/NE.I 1739-A (2); Sald. N/NE.I 1784 (3); Sald. N/NE.I 1807 (1); Sald. N/NE.I 1817-A (3); Sald. N/NE.II 1872 (1); Sald. N/NE.II 1892 (11); Sald. N/NE.II 1921 (4); P.N I Dg2 (4); PE.36-A (1); ITA. 19(1);PEC.03 (2);REC.27(2);REC.29(1); REC.148(1); Rec. 156 (3).

DISTRIBUIÇÃO GEOGRÁFICA: Carolina do Norte, Flórida, Golfo do México, Antilhas e Brasil: Amapá, Pará, Maranhão, Rio Grande do Norte e Pernambuco (Fernando de Noronha).

\section{Gênero Neodrillia Bartsch, 1943}

Concha cônica, alongada, de espira alta e base truncada; canal sifonal curto; com costelas axiais fortes e numerosas estrias espirais. Sinus pouco profundo, em forma de U inclinado sobre o ombro. Protoconcha com 2,5 voltas, a primeira lisa e o restante estriado axialmente. Tipo: $N$. cydia Bartsch, 1943.

Neodrillia cydia Bartsch, 1943 - (Figura 18).

SINÔNIMO: Neodrillia antiguensis, N. encia, N. barbadensis, N. jamaicencis, Bartsch, 1943 (Rios, 1994); Drillia cydia Bartsch,1943;Drillia (Neodrillia) cydia (Bartsch,1943); Inodrillia ustickei Hayes, 1959 (Maes, 1983).

DIAGNOSE: Concha pequena (15 x 6mm) cônica, robusta, de espira elevada e margem anterior truncada, seis voltas. Ângulo da espira $=35^{\circ}$. Esculturas com nove costelas longas cruzadas por numerosas linhas iniciais que fazem com que a superfície seja opaca e áspera cor branca, ocasionalmente com pontos marrom sobre as costelas.

COMENTÁRIOS: Material dragado entre 15,5 a 160 metros de profundidade, proveniente de fundos de areia, algas calcárias, lama, organogênico, Halimeda e detrítico.

MATERIAL EXAMINADO: GM.I 27 (1); GM.I 43 (1); GM.I 47 (5); GM.I 60 (8); Sald. N/NE.I 1657 (1); Sald. N/NE.I 1663-A (2); Sald. N/NE.I 1663-C (1); Sald. N/NE.I 1667-A (5); Sald. N/NE.I 1668 (2); Sald. N/NE.I 1688 (1); Sald. N/NE.I 1718 (3); Sald. N/NE.I 1719-A (3); Sald. N/NE.I 1723 (1); Sald. N/NE.I 1739-A (1); Sald. N/NE.I 1773-A (2); Sald. N/NE.I 1817-A (1); Sald. N/NE.I 1807-A (1); PE.06 (1); ITA. 98 (1); ITA. 102 (1); REC. 20 (1); REC. 27 (1); REC. 38 (1); REC. 108 (3); REC. 112 (1); REC. 113 (1); REC. 143 (1).

DISTRIBUIÇÃO GEOGRÁFICA: Flórida, Antilhas e Brasil (Amapá; Pará; Maranhão; Ceará; Rio Grande do Norte - Atol das Rocas; Pernambuco - Fernando de Noronha; Alagoas).

\section{CONSIDERAÇÕES ECOLÓGICAS E DE DISTRIBUIÇÃo GEOGRÁFICA}

Foi verificada que as espécies da subfamília Drilliinae ocorreram em maior quantidade em três tipos de substrato: arenoso com 20\%; lamoso com 19\% e de algas calcárias com 17\% (Figura 19). Menos de $10 \%$ das espécies ocorreram nos demais tipos de fundo.

Alguns autores citam os substratos areno-lamosos como predominantes na distribuição dos representantes de Drilliinae, como Rios (1994) e Merlano \& Hegedus (1997). 
As espécies Clathrodrillia minor, Splendrillia tantula, Leptadrillia cookei, Leptadrillia splendida, Cerodrillia perryae e Neodrillia cydia, tiveram ampla distribuição no que se refere ao tipo de substrato, sendo bem representadas em todos os ambientes.

A espécie Clathrodrillia paria (Reeve, 1846) é citada por Rios (1994) em fundos de algas calcárias, todavia foi encontrada em fundos de arreia e lama (Figura 20).

A abundância dos turrídeos em número de espécies é relatada por Keen (1971) como um provável resultado dos seus hábitos predatórios.

A espécie Neodrillia cydia Bartsch, 1943 é citada por Maes (1983) como predadora de sipunculideos.

Com relação à profundidade a maioria das espécies foi coletada em profundidades compatíveis com a plataforma continental das regiões estudadas. (Figura 20)

As profundidades entre 40 a 80 metros foram as que concentraram maior número de espécies. A espécie Neodrillia cydia Barstch, 1943 foi coletada a 160 metros, a maior profundidade registrada nas estações. Splendrillia carolinae (Bartsch, 1934), foi dragada a 13 metros de profundidade, porém é citado por Rios (1995), para 100 metros.

Na costa Norte e Nordeste do Brasil, os representantes de Drilliinae estudados apresentam distribuição em geral desde o Estado do Amapá até o Estado de Pernambuco, entretanto, a bibliografia menciona também a costa Sudeste e Sul brasileira para algumas espécies. (Tabela 2)

Dentre as 18 espécies coletadas na área,dez foram encontradas apenas no norte e nordeste,5 ocorrem também no sudeste e 3 se distribuem também na região sul, formando assim três grupos.

As seguintes espécies tiveram ampliados seus registros de distribuição para o Norte e Nordeste do Brasil: Para a costa Norte: Spirotropis lithocolleta, Drilliola comatotropis, Clathrodrillia albicoma, Splendrillia coccinata, S. carolinae e Neodrillia cydia; para a costa Nordeste: Clathrodrillia gibbosa, C. minor, Splendrillia lissotropis, S. tantula, S. woodring, Leptadrillia cookei, L. splendida e Cerodrillia perryae.

As espécies são tropicais e apresentam distribuição geográfica geral, desde a costa Leste Norte Americana (Flórida), Antilhas, América Central e Brasil.

\section{DISCUSSÃo}

A família Turridae Swainson (1840) compreende um grupo problemático cujos gêneros têm sido diversamente interpretados por diferentes autores. A dificuldade se deve em parte, a multiplicidade de gêneros que têm sido relatados.

Nos trabalhos de Dall (1920), Bartsch (1934) e Powell (1942), há unanimidade de opiniões sobre a dificuldade encontrada na classificação dos Turrídeos, devendo-se a vários fatores, o principal deles a existência de numerosas espécies, poucas do mediolitoral, e muitas conchas sem partes moles. Esta escassez de representantes capturados vivos é refletida nas pouquíssimas espécies que têm sido descritas anatomicamente, muitos dos gêneros são baseados em formas fósseis, e a avaliação desses gêneros é dependente de comparações superficiais com formas recentes. Muitas vezes,tais comparações estão baseadas principalmente nos caracteres conquiológicos como a protoconcha, a forma e posição do sinus, a presença ou ausência do entalhe estromboide, ornamentação, etc. A determinação dessas características e da morfologia da rádula e opérculo, juntamente com as partes moles é de extrema importância na identificação das espécies.

De acordo com Powell (1966),a família Turridae tem como sinônimos as respectivas famílias: Pleurotomariidae Swainson, 1840, Turridae H \& A. Adams, 1853; Pleurotomariidae Chenu, 1859 e Turridae Hedley, 1922. Com relação aos gêneros, no século XIX as poucas espécies deste grupo se reuniam principalmente no gênero Pleurotoma Lamarck, 1799 (Lindner, 1975). Este nome seria um indicativo do entalhe da boca (pleurón = lado, toma = corte); entretanto, devido a causas de prioridade, foi modificado para a denominação mais antiga Turris Roding, 1798, nome

Tropical Oceanography, Recife: v. 30, n. 1, p. 59-90, 2002 
também usado por Magalhães \& Mezzalira (1953). As discussões sobre sinonímia prosseguiram desta vez sobre as subfamílias. Autores como Powell (op. cit.), Keen (1971), Abbott (1974), Maes (1983), Merlano e Hegedus (1997), mencionam a subfamília Clavinae Powell, (1942), entretanto Rios (1994) cita a subfamília Drilliinae Morrison, 1966. Ambas são sinônimas, porém, muitos representantes dos Clavinae foram deslocados para outras subfamílias. O referido autor não relata o porquê dessa mudança, todavia, comparando-se as descrições de outras subfamílias verifica-se que o tipo de rádula foi a provável causa dessa mudança, no presente trabalho,portanto, segue-se à nomenclatura deste último autor.

No material estudado foram encontrados nove gêneros e dezoito espécies da subfamília Drilliinae. Dentre os gêneros encontrados, Splendrillia e Clathrodrillia foram os mais representativos em quantidade de espécies e indivíduos; Rio (1994) cita onze gêneros e trinta e quatro espécies distribuídas na costa brasileira e Keen (1971) afirma,ainda,que a rádula prova ser o mais sério caractere para identificação dos Turrideos, ainda que necessite levar em consideração uma combinação de outros caracteres.

Três novas espécies de Turrideos foram descritas por Lyons (1972), sendo uma delas Cerodrillia girardi pertencente à subfamília Drilliinae, muito semelhante a C. perryae, porém mais globosa. Semelhanças também foram encontradas entre Fenimorea halidorema Schwengel, 1940 e F. janetae Bartsch, 1934, por Rios, (1995), esta última apresenta-se mais larga e possui um maior número de voltas (dez) em relação à espécie anterior. O número de voltas foi também importante para diferenciar Leptadrillia splendida de Leptadrillia cookei assim como lábio interno comprido e columela com uma forte calosidade fato observado por Merlano e Hegedus (op. cit.). Estes autores também mencionam diferenças entre Clathrodrillia gibbosa (Born, 1778) e C. Minor (Dautzenberg, 1900) com relação ao tamanho e tipo de ornamentação, a primeira apresentando costela axiais cruzadas por numerosos cordões espirais; a segunda com linhas incisas que não cruzam sobre as costelas axiais. Espécies de C. minor de águas relativamente profundas têm uma ornamentação mais visível do que as de águas rasas. Esta afirmação confirma as observações feitas com o material analisado.

Observações sobre a biologia e sistemática dos Turrideos das Ilhas Virgens foram feitas por Maes (1983), espécimens de Neodrillia cydia apresentam um dimorfismo sexual relacionado com as variações de coloração e tamanho da concha, estas variantes são as causas dos seus numerosos sinônimos. Fêmeas desta e de outras espécies da comunidade de moluscos são maiores do que os machos. As espécies analisadas apresentaram uma variedade de tamanhos. Maes (op. cit.) cita espécies de Neodrillia cydia presentes no estômago de estrelas-do-mar e em águas rasas da Carolina do Norte.

O substrato arenoso destacou-se por ser habitado pelo maior número de espécimens completos, os pertencentes ao gênero Splendrillia Hedley, 1922 citados por Rios (1994), foram coligidos em sua maioria em substrato areno-lamoso; essa afirmação concorda com os dados obtidos nesta pesquisa, exceto as espécies Splendrillia lissotropis (Dall, 1881) e S. carolinae (Bartsch, 1934) coligidas em fundos de algas calcárias e areia, respectivamente. Tabb \& Manning (1960) estudando a fauna e flora do Nordeste da Bahia citam cinco espécies de Turrideos entre elas, Cerodrillia perryae Bartsch \& Rehder, 1939 e Cerodrillia thea (Dall, 1883) são comuns em comunidades de algas do gênero Thalassia.

Em geral, os Turridae são citados como habitantes de águas profundas, fato também observado para as espécies de Drilliinae analisados cuja maior concentração se deu entre os 40 e 120 metros. Nessa faixa de profundidade, Merlano e Hegedus (op. cit.), citam a espécie Leptadrillia splendida Bartsch, 1934, como rara em fundos lodosos entre 40 e 80 metros de profundidade e (Rios, 1995) relata esta espécie em fundos arenosos na costa paraense entre 30 e 100 metros de profundidade.

Tropical Oceanography, Recife: v. 30, n. 1, p. 59-90, 2002 
As espécies Clathrodillia minor, Cerodrillia perreyae e Neodrillia cydia. foram as mais freqüentes nas estações.

Dentre os exemplares estudados verifica-se a existência de espécies que apresentam uma distribuição geográfica semelhante, estando representadas desde a Carolina do Norte, Flórida, Antilhas, e no Brasil, a maioria se distribui entre o Amapá e Pernambuco, algumas até a Bahia e as demais entre o Espírito Santo e Rio Grande do Sul. Não se pode afirmar todavia a continuidade dessa distribuição,o que há é falta de registros nos setores intermediários, provavelmente devido a coletas insuficientes nestas áreas. Apenas uma espécie, Clathrodrillia gibbosa (Kiener, 1840), tendo como sinônimo Crassispira (Clathrodrillia) gibbosa (Born, 1778), foi citada por Wenz (1944) para o oceano Índico. Foi verificado que do total de espécies identificadas na área estudada, 55\% apresentam registros apenas no Norte e Nordeste, 28\% ocorrem também na costa Sudeste e 17\% alcançam o litoral Sul do Brasil.

\section{CONCLUSÕES}

Na costa Norte e Nordeste do Brasil foram identificados nove gêneros e dezoito espécies de Drilliinae de um total de 278 indivíduos

O gênero Splendrillia foi o mais representativo em número de espécies seguido por Clathrodrillia. Entre as espécies estudadas Cerodrillia perryae Bartsch \& Rehder, 1939 foi a mais abundante em número de indivíduos.

Das espécies estudadas, Clathrodrillia minor (Dauzenberg, 1900) foi a mais abundante com 82 espécimens, seguida por Cerodrillia peryae Bartsch \& Rehder, 1939 com 63 e Neodrillia cydia Bartsch, 1943, com 51 indivíduos.

Nas estações estudadas Neodrillia cydia Bartsch, 1943 foi a mais freqüente em 28 estações, seguida por Cerodrillia perryae Bartsch \& Rechder, 1939 em 24 estações e Clathrodrillia minor (Dautzenberg, 1900) em 22 estações.

As profundidades entre 40 e 120 metros foram a que concentraram o maior número de espécies. Clathrodrillia gibbosa (Kiener, 1840), C. albicoma (Dall, 1889) Fenimorea halidorema Schwengel, 1940, Cerodrillia perryae Bartsch \& Rehder, 1939 e Neodrillia cydia ocorreram em profundidades superiores a 100 metros.

As espécies foram predominantes em substrato arenoso e lamoso.

Espécies com distribuição apenas no norte e nordeste do Brasil - Drilliia interpleura, Clatrodrillia gibbosa, Clathrodrillia minor, Splendrillia coccinata, Splendrillia tantula, Splendrillia woodring, Leptadrillia cookei, Leptadrillia splendida, Fenimorea haliodrema e Neodrillia cydia. 2. Espécies ocorrentes também no sudeste - Clathrodrillia paria, Clathrodrillia albicoma, Splendrillia lissotropis, Cerodrillia thea e Cerodrillia perryae; 3. Espécies presentes no norte, nordeste e sul Spirotropis lithocoleta, Drilliola comatotropis e Splendrillia carolinae.

Spirotropis lithocolleta, Drilliola comatotropis, Clathrodrillia albicoma, Splendrillia coccinata, S. carolinae e Neodrillia cydia constituem nova ocorrência para a costa Nordeste e Clathrodrillia gibbosa, C. minor, Splendrillia lissotropis, S. tantula, S. woodring, Leptadrillia cookei, L. splendida e Cerodrillia perryae são para a região norte. 


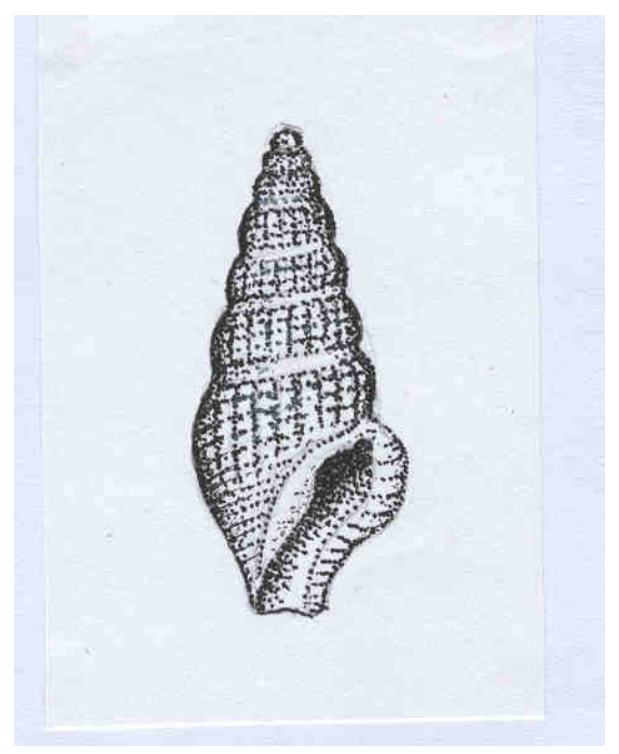

Figura 1 - Drillia interpleura Dall \& Simpson, 1901 (6x).

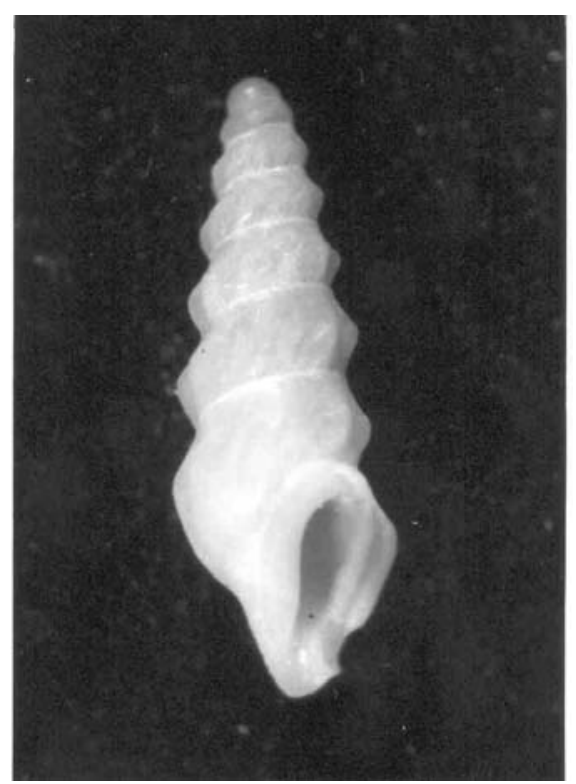

Figura 2 - Spirotropis lithocolleta (Watson, 1881) (12x)

Tropical Oceanography, Recife: v. 30, n. 1, p. 59-90, 2002 


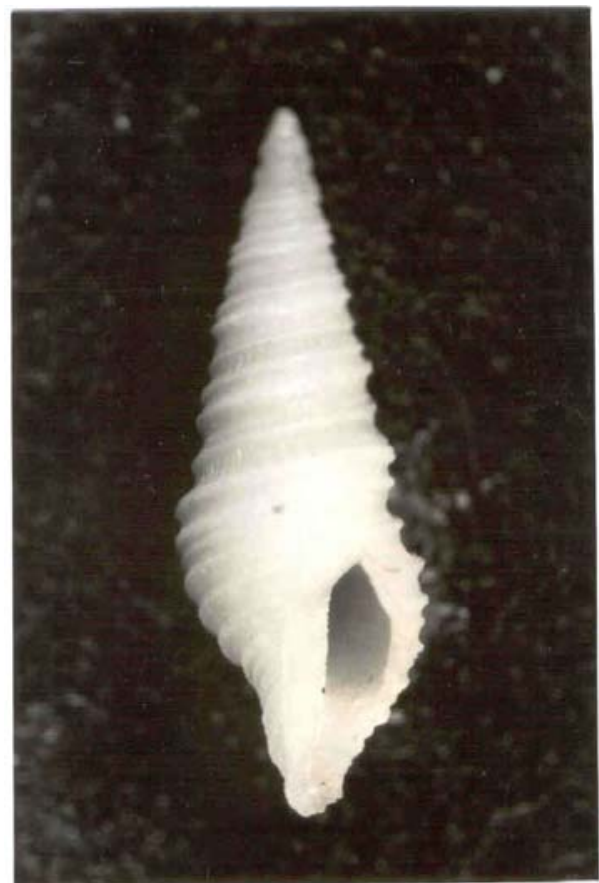

Figura 3 - Drilliola comatotropis (Dall, 1881) (12x)

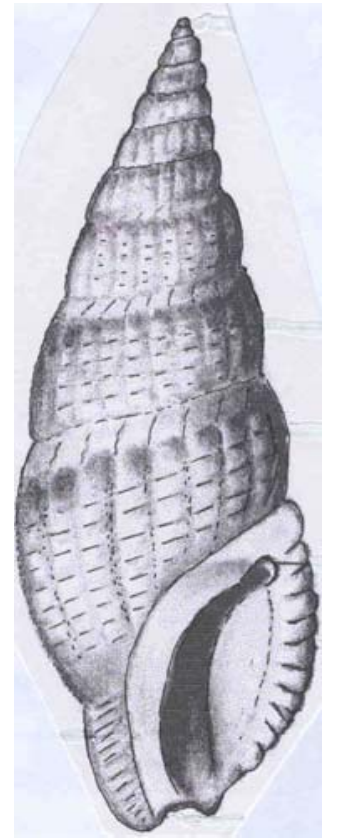

Figura 4 - Clathrodrillia gibbosa (Kiener, 1840) (12x)

Tropical Oceanography, Recife: v. 30, n. 1, p. 59-90, 2002 


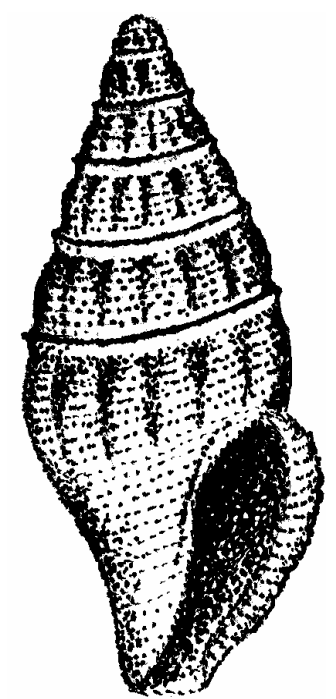

Figura 5 - Clathrodrillia paria (Reeve, 1846) (9x)

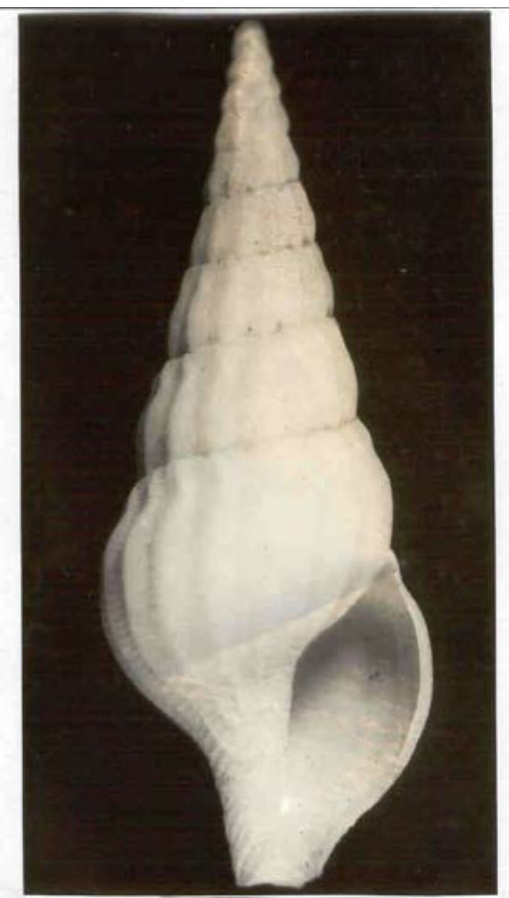

Figura 6 - Clathrodrillia albicoma (Dall, 1889) (8x)

Tropical Oceanography, Recife: v. 30, n. 1, p. 59-90, 2002 


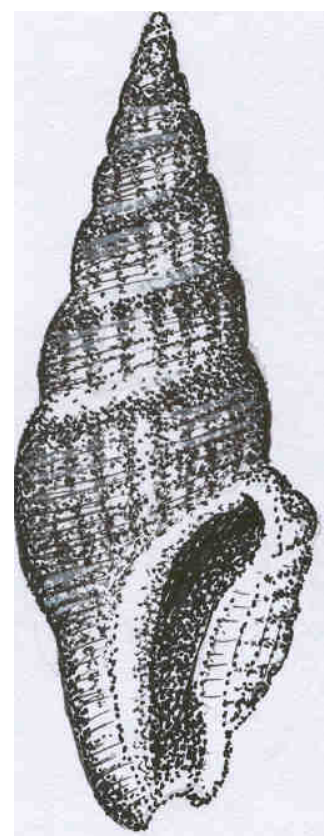

Figura 7 - Clathrodrillia minor (Dautzenberg, 1900) (6x)

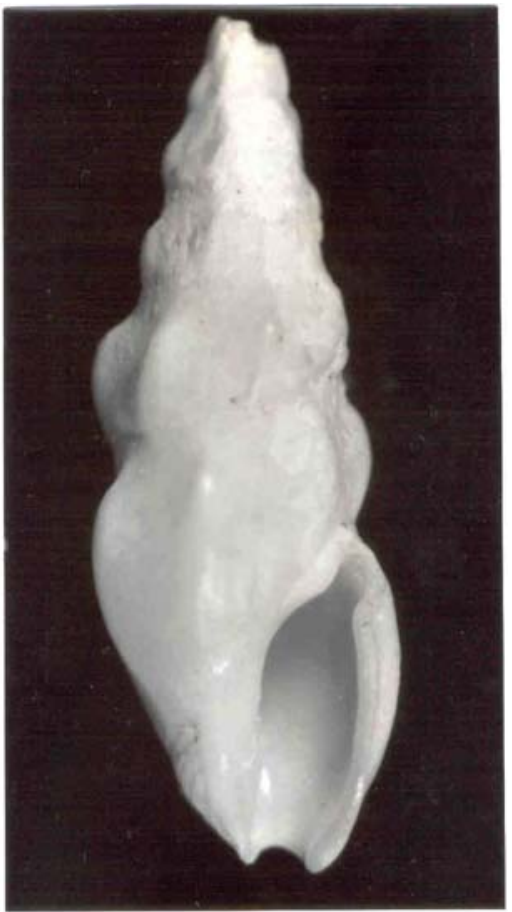

Figura 8 - Splendrillia coccinata (Reeve, 1845) (13x)

Tropical Oceanography, Recife: v. 30, n. 1, p. 59-90, 2002 


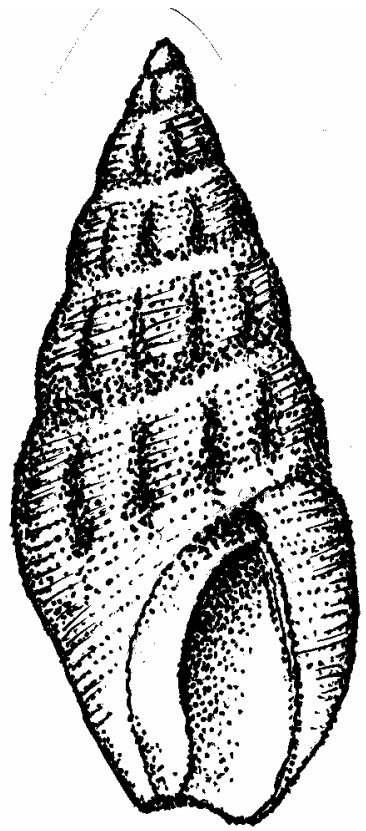

Figura 9 - Splendrillia lissotropis (Dall, 1881) (8x)

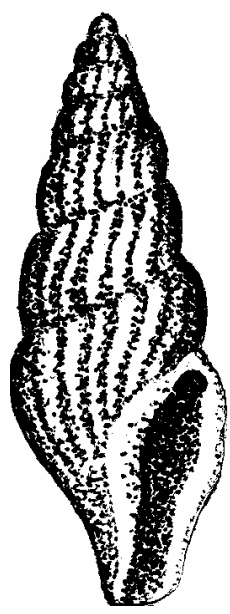

Figura 10 - Splendrillia carolinae (Bartsch, 1934) (3x). 


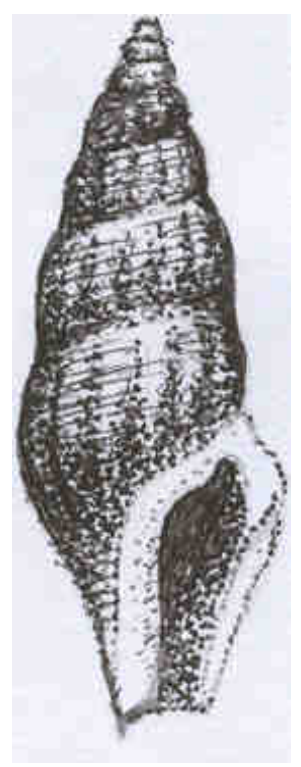

Figura 11 - Splendrillia woodringi (Bartsch, 1934) (6x).

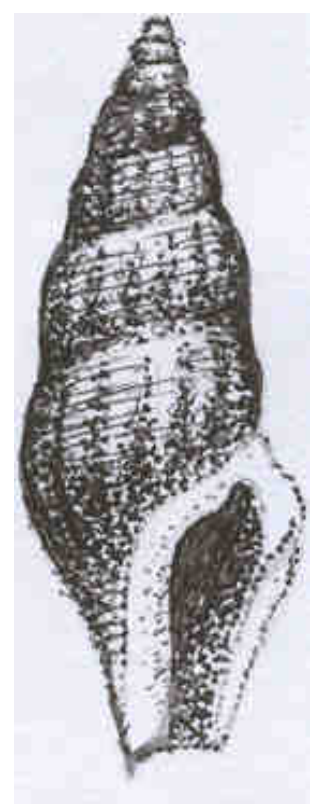

Figura 12 - Splendrillia tantula (Bartsch, 1934) (6x). 


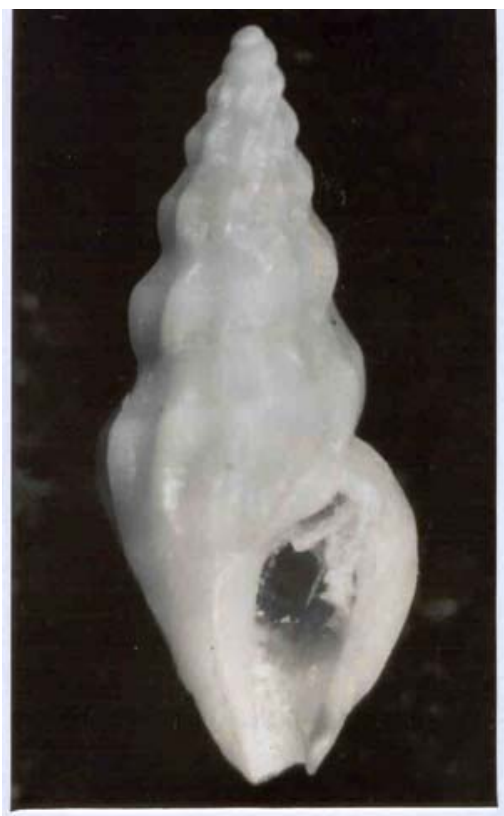

Figura 13 - Leptadrillia cookei (E. A. Smith, 1888) (13v)

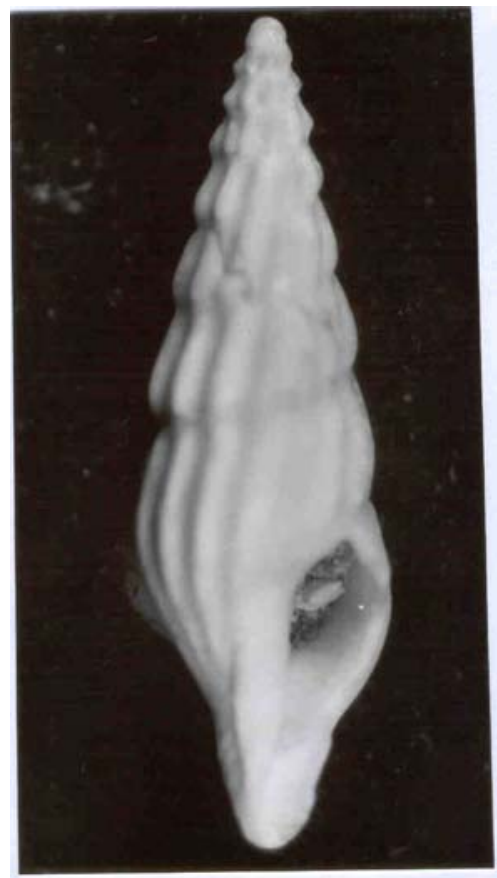

Figura 14 - Leptadrillia splendida (Bartsch, 1934) (13x)

Tropical Oceanography, Recife: v. 30, n. 1, p. 59-90, 2002 


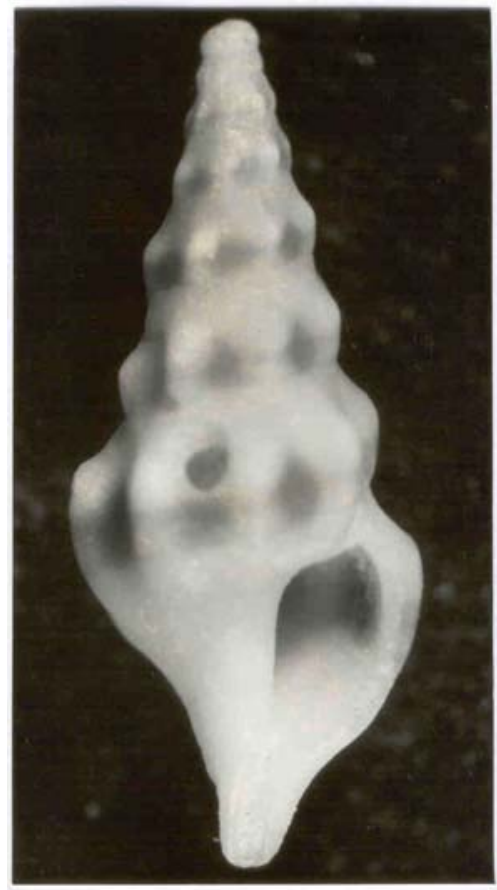

Figura 15 - Fenimorea halidorema Schwengel, 1940) (13x).

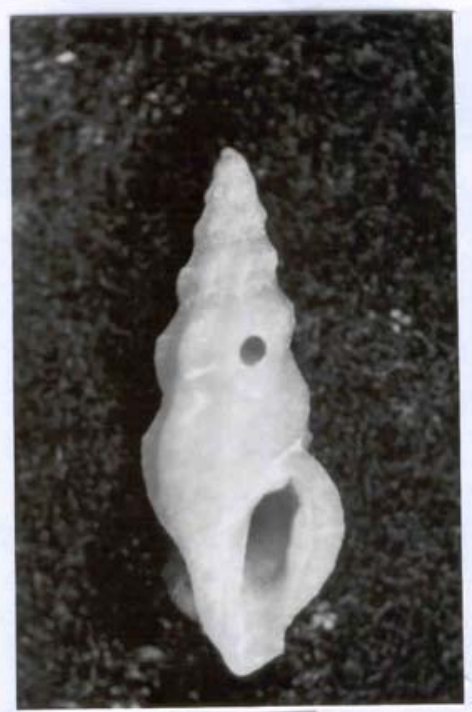

Figura 16 - Cerodrillia thea (Dall, 1883) (17x).

Tropical Oceanography, Recife: v. 30, n. 1, p. 59-90, 2002 


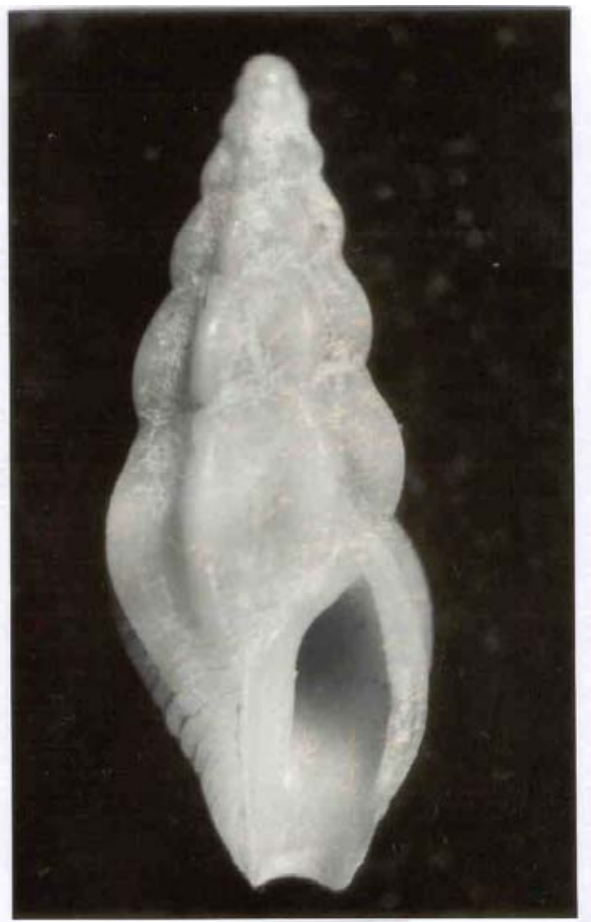

Figura 17 - Cerodrillia perryae Bartsch \& Rehder, 1939 (14x).

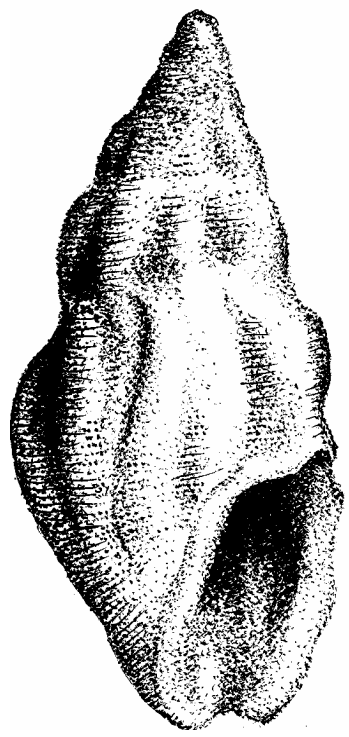

Figura 18 - Neodrillia cydia Bartsch, 1943) (8x).

Tropical Oceanography, Recife: v. 30, n. 1, p. 59-90, 2002 


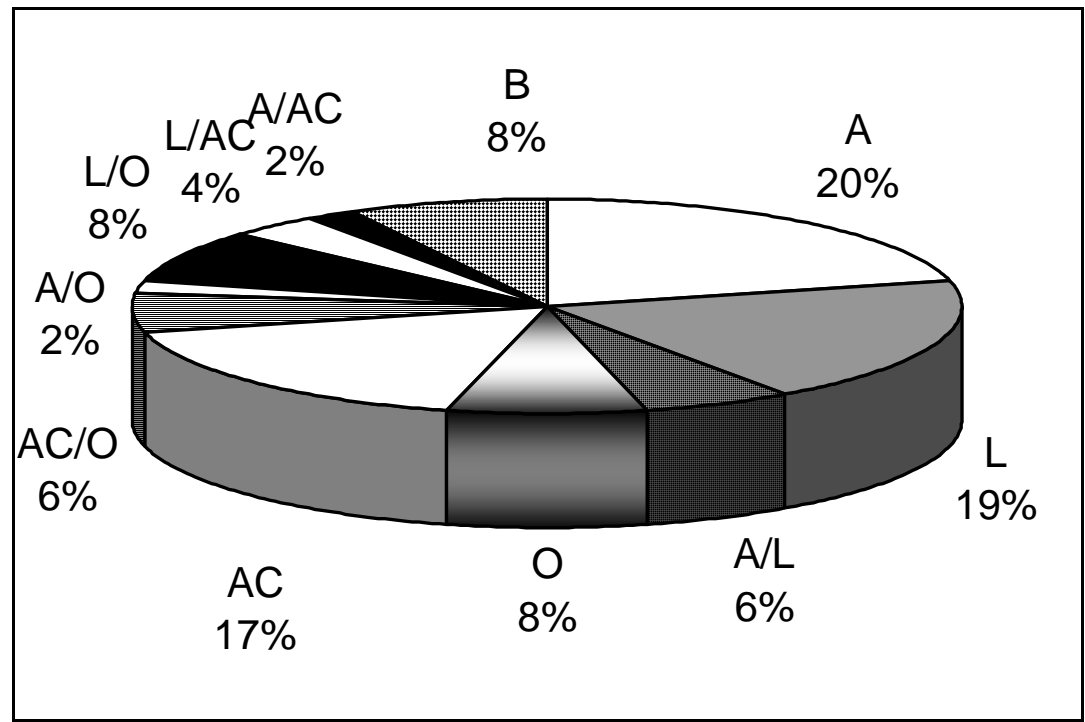

Figura 19 - Freqüência relativa das espécies de moluscos da subfamília Drilliinae nos diversos tipos de substrato.

Legendas: $\mathrm{A}=$ Areia; $\mathrm{L}=$ Lama; $\mathrm{A} / \mathrm{L}=$ Areia e Lama; $\mathrm{O}=$ Organogênico; $\mathrm{AC}=$ Algas calcárias; AC/O = Algas Calcárias e Organogênico; A/O = Areia e Organogênico; L/O = Lama e Organogênico; L/AC = Lama e Algas Calcárias; B = Biodetrítico; A/AC = Areia e Algas Calcárias.

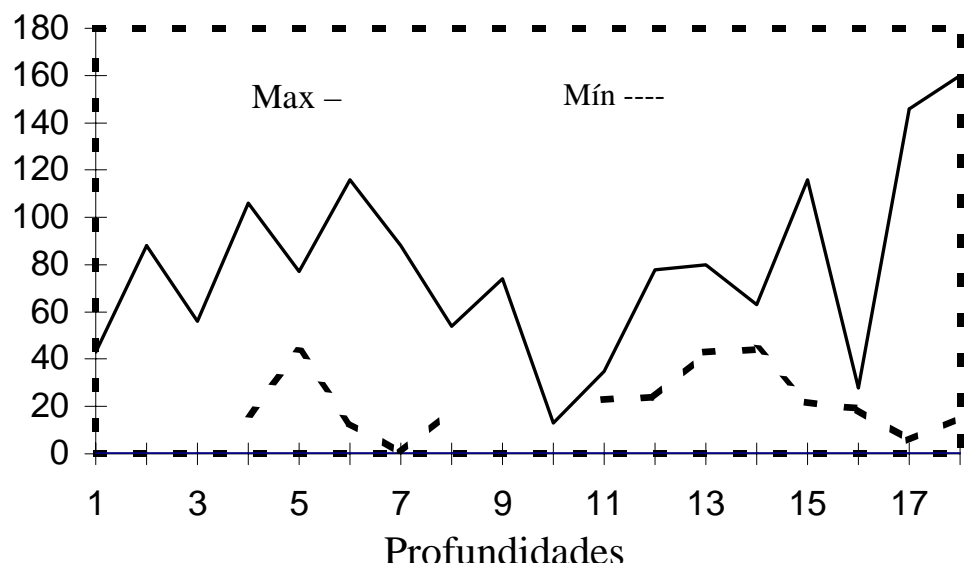

Legenda: 1 Drillia interpleura; 2 Spirotropis lithocolleta; 3 Drilliola comatotropis; 4 Clathrodrillia gibbosa; 5 Clathrodrillia paria; 6 Clathrodrillia albicoma; 7 Clathrodrillia minor; 8 Splendrillia coccinata; 9 Splendrillia lissotropis; 10 Splendrillia carolinae; 11 Splendrillia tantula; 12 Splendrillia woodringi; 13 Leptadrillia cookei; 14 Leptadrillia splendida; 15 Fenimorea halidorema; 16 Cerodrillia thea; 17 Cerodrillia perryae; 18 Neodrillia cydia.

Figura 20 - Distribuição Batimétrica dos moluscos da subfamília Drilliinae:

Tropical Oceanography, Recife: v. 30, n. 1, p. 59-90, 2002 
Tabela 1 - Lista das Comissões Oceanográficas com as estações estudadas,coordenadas geográficas, profundidade (em metros) e tipo de sedimento.

Geomar I (1968)

\begin{tabular}{|c|c|c|c|c|c|}
\hline Estação & Latitude & Longitude & Prof. (m) & Fundo & Localidade \\
\hline 08 & $02^{\circ} 04^{\prime} 0^{\prime \prime} \mathrm{S}$ & $42^{\circ} 43^{\prime} 0^{\prime \prime}$ & 67 & A & MA \\
\hline 21 & $00^{\circ} 14^{\prime} 5^{\prime \prime} \mathrm{N}$ & $45^{\circ} 04^{\prime} 2^{\prime \prime}$ & 73 & B & MA \\
\hline 22 & $00^{\circ} 00^{\prime} 0 ” \mathrm{~N}$ & $45^{\circ} 37^{\prime} 0^{\prime \prime}$ & 65 & $\mathrm{~A}$ & MA \\
\hline 27 & $00^{\circ} 02^{\prime} 5$ ”'S & $46^{\circ} 15^{\prime} 0^{\prime \prime}$ & 42 & $\mathrm{~A}$ & MA \\
\hline 29 & $00^{\circ} 38^{\prime} 0 ” \mathrm{~N}$ & $45^{\circ} 52^{\prime} 5^{\prime \prime}$ & 75 & $\mathrm{~B}$ & MA \\
\hline 33 & 00¹1'5”S & $46^{\circ} 49^{\prime} 5^{\prime \prime}$ & 29 & $\mathrm{~A}$ & MA \\
\hline 34 & $00^{\circ} 21^{\prime} 0$ ”'S & 4658’0”' & 30 & $\mathrm{~A}$ & MA \\
\hline 41 & $01^{\circ} 17^{\prime} 0 ” \mathrm{~N}$ & $46^{\circ} 57^{\prime} 5^{\prime \prime}$ & 55 & $\mathrm{~A}$ & MA \\
\hline 42 & $01^{\circ} 28$ '0”N & $46^{\circ} 51^{\prime} 0^{\prime \prime}$ & 80 & $\mathrm{~B}$ & MA \\
\hline 43 & $01^{\circ} 33^{\prime} 0 ” \mathrm{~N}$ & $46^{\circ} 49^{\prime} 0^{\prime \prime}$ & $120-160$ & $\mathrm{AC}$ & MA \\
\hline 46 & $01^{\circ} 05^{\prime} 0 ” \mathrm{~N}$ & $47^{\circ} 42^{\prime} 5^{\prime \prime}$ & 63 & $\mathrm{~L}$ & PA \\
\hline 47 & $00^{\circ} 37^{\prime} 0 ” \mathrm{~N}$ & 4751'0”' & 43 & $\mathrm{~L}$ & PA \\
\hline 54 & $01^{\circ} 34^{\prime} 0 ” \mathrm{~N}$ & $48^{\circ} 07^{\prime} 0 ”$ & 50 & $\mathrm{~A}$ & PA \\
\hline 57 & $02^{\circ} 01^{\prime} 0 ” \mathrm{~N}$ & $47^{\circ} 49^{\prime} 5^{\prime \prime}$ & 77 & A & PA \\
\hline 60 & 01³7’7”N & 49॰03’1” & 14 & $\mathrm{~L}$ & AP \\
\hline
\end{tabular}

Norte e Nordeste I (1967)

\begin{tabular}{|c|c|c|c|c|c|}
\hline Estação & Latitude & Longitude & Prof. (m) & Fundo & Localidade \\
\hline 1657 & 05³3'4"S & $35^{\circ} 00^{\prime} 2^{\prime \prime}$ & 53 & AC & RN \\
\hline 1663-A & 0349'6"S & $33^{\circ} 49^{\prime} 2^{\prime \prime}$ & 53 & AC & RN \\
\hline $1663-\mathrm{C}$ & 0354'8”S & $33^{\circ} 46^{\prime} 4^{\prime \prime}$ & 60 & $\mathrm{AC} / \mathrm{h}$ & RN \\
\hline 1667-A & $03^{\circ} 50^{\prime} 7 " \mathrm{~S}$ & $32^{\circ} 28^{\prime} 1^{\prime \prime}$ & 65 & $\mathrm{AC}$ & RN \\
\hline 1668 & 0353’0"S & $32^{\circ} 37^{\prime} 2^{\prime \prime}$ & 60 & $\mathrm{AC}$ & RN \\
\hline 1668-A & 0353’0”S & $32^{\circ} 37^{\prime} 2^{\prime \prime}$ & 90 & $\mathrm{AC} / \mathrm{O}$ & RN \\
\hline 1684-B & 0359'5”S & 355’’” & 73 & AC & RN \\
\hline 1688 & 04³3’5”S & $36^{\circ} 58^{\prime} 0 ”$ & 49 & $\mathrm{~A}$ & RN \\
\hline 1693 & 03³0’0”S & $37^{\circ} 56^{\prime} 5^{\prime \prime}$ & 49 & $\mathrm{AC} / \mathrm{O}$ & $\mathrm{CE}$ \\
\hline 1718 & $02^{\circ} 07^{\prime} 0 " S$ & $40^{\circ} 36^{\prime} 0^{\prime \prime}$ & 71 & $\mathrm{AC} / \mathrm{O}$ & $\mathrm{CE}$ \\
\hline 1719-A & $02^{\circ} 21^{\prime} 5^{\prime \prime} \mathrm{S}$ & $40^{\circ} 29^{\prime} 5^{\prime \prime}$ & 37 & $\mathrm{~A}$ & $\mathrm{CE}$ \\
\hline 1723 & $02^{\circ} 00^{\prime} 0 " S$ & $41^{\circ} 01^{\prime} 0 ”$ & 73 & $\mathrm{CA} / \mathrm{O}$ & $\mathrm{CE}$ \\
\hline 1730 & $02^{\circ} 37^{\prime} 0 ” S$ & $41^{\circ} 27^{\prime} 5 ”$ & 21 & $\mathrm{AC}$ & $\mathrm{CE}$ \\
\hline 1738-A & 0155'5”S & $42^{\circ} 45^{\prime} 0 ”$ & 75 & $\mathrm{~A} / \mathrm{O}$ & MA \\
\hline 1739-A & $02^{\circ} 14^{\prime} 0^{\prime \prime S}$ & $42^{\circ} 43^{\prime} 0^{\prime \prime}$ & 35 & $\mathrm{~A}$ & MA \\
\hline 1751 & 00³7’0"S & $44^{\circ} 40^{\prime} 0 ”$ & 44 & $\mathrm{~A} / \mathrm{AC}$ & MA \\
\hline 1754 & 0006’0"S & 4550’0”' & 51 & $\mathrm{~A}$ & MA \\
\hline
\end{tabular}


Norte e Nordeste I (1967)

\begin{tabular}{|l|c|c|c|c|c|}
\hline Estação & Latitude & Longitude & Prof. (m) & Fundo & Localidade \\
\hline 1755 & $00^{\circ} 37^{\prime} 5^{\prime} \mathrm{N}$ & $45^{\circ} 38^{\prime} 5^{\prime}$ & 80 & $\mathrm{AC}$ & $\mathrm{MA}$ \\
\hline 1763 & $00^{\circ} 25^{\prime} 0^{\prime} \mathrm{S}$ & $47^{\circ} 17^{\prime} 0^{\prime}$ & 23 & $\mathrm{~A}$ & $\mathrm{PA}$ \\
\hline 1767 & $01^{\circ} 32^{\prime} 5^{\prime} \mathrm{N}$ & $47^{\circ} 24^{\prime} 5^{\prime}$ & 63 & $\mathrm{AC} / \mathrm{O}$ & $\mathrm{PA}$ \\
\hline $1773-\mathrm{A}$ & $02^{\circ} 28^{\prime} 0^{\prime} \mathrm{N}$ & $48^{\circ} 13^{\prime} 5^{\prime}$ & 85 & $\mathrm{~A}$ & $\mathrm{AP}$ \\
\hline 1784 & $03^{\circ} 08^{\prime} 5^{\prime} \mathrm{N}$ & $48^{\circ} 07^{\prime} 0^{\prime}$ & 85 & $\mathrm{~L} / \mathrm{O}$ & $\mathrm{AP}$ \\
\hline $1787-\mathrm{A}$ & $03^{\circ} 31^{\prime} 5{ }^{\prime} \mathrm{N}$ & $50^{\circ} 11^{\prime} 0^{\prime}$ & 75 & $\mathrm{~L}$ & $\mathrm{AP}$ \\
\hline 1807 & $00^{\circ} 13^{\prime} 0^{\prime} \mathrm{S}$ & $44^{\circ} 46^{\prime} 0^{\prime}$ & 54 & $\mathrm{~A} / \mathrm{AC}$ & $\mathrm{PA}$ \\
\hline $1807-\mathrm{A}$ & $00^{\circ} 01^{\prime} 5^{\prime} \mathrm{S}$ & $44^{\circ} 35^{\prime} 5^{\prime}$ & 72 & $\mathrm{AC}$ & $\mathrm{PA}$ \\
\hline 1813 & $01^{\circ} 29^{\prime} 0^{\prime} \mathrm{S}$ & $43^{\circ} 19^{\prime} 0^{\prime}$ & 83 & $\mathrm{O} / \mathrm{AC}$ & $\mathrm{MA}$ \\
\hline $1817-\mathrm{A}$ & $02^{\circ} 07^{\prime} 8^{\prime} \mathrm{S}$ & $42^{\circ} 26^{\prime} 2^{\prime}$ & 73 & $\mathrm{~L} / \mathrm{O}$ & $\mathrm{MA}$ \\
\hline
\end{tabular}

Norte e Nordeste II (1968)

\begin{tabular}{|l|c|c|c|c|c|}
\hline Estação & Latitude & Longitude & Prof. (m). & Fundo & Localidade \\
\hline 1855 & $04^{\circ} 56^{\prime} 5^{\prime} \mathrm{S}$ & $35^{\circ} 22^{\prime}{ }^{\prime}{ }^{\prime}$ & 30 & $\mathrm{AC}$ & $\mathrm{PA}$ \\
\hline 1857 & $03^{\circ} 35^{\prime} 0^{\prime} \mathrm{S}$ & $37^{\circ} 57^{\prime} 0^{\prime}$ & 43 & $\mathrm{AC}$ & $\mathrm{CE}$ \\
\hline 1860 & $0^{\circ} 26^{\prime} 0^{\prime} \mathrm{S}$ & $38^{\circ} 30^{\prime} 0^{\prime}$ & 35 & $\mathrm{~A}$ & $\mathrm{CE}$ \\
\hline 1872 & $0^{\circ} 20^{\prime} 0^{\prime} \mathrm{S}$ & $43^{\circ} 33^{\prime} 50^{\prime}$ & 53 & $\mathrm{~A} / \mathrm{O}$ & $\mathrm{MA}$ \\
\hline 1889 & $02^{\circ} 23^{\prime} 0^{\prime} \mathrm{S}$ & $47^{\circ} 16^{\prime} 10^{\prime}$ & 31 & $\mathrm{~A}$ & $\mathrm{PA}$ \\
\hline 1892 & $01^{\circ} 45^{\prime} 0^{\prime} \mathrm{N}$ & $48^{\circ} 18^{\prime} 00^{\prime}$ & 56 & $\mathrm{~A}$ & $\mathrm{PA}$ \\
\hline 1906 & $02^{\circ} 40^{\prime} 0^{\prime} \mathrm{N}$ & $49^{\circ} 00^{\prime} 00^{\prime}$ & 78 & $\mathrm{~A}$ & $\mathrm{AP}$ \\
\hline 1910 & $03^{\circ} 28^{\prime} 5^{\prime} \mathrm{N}$ & $49^{\circ} 52^{\prime} 00^{\prime}$ & 70 & $\mathrm{~A}$ & $\mathrm{AP}$ \\
\hline 1912 & $03^{\circ} 49^{\prime} 0^{\prime} \mathrm{N}$ & $49^{\circ} 40^{\prime} 00^{\prime}$ & 106 & $\mathrm{~A} / \mathrm{O}$ & $\mathrm{AP}$ \\
\hline 1921 & $04^{\circ} 30^{\prime} 0^{\prime} \mathrm{N}$ & $50^{\circ} 03^{\prime} 00^{\prime}$ & 146 & $\mathrm{~A}$ & $\mathrm{AP}$ \\
\hline
\end{tabular}

Norte e Nordeste IV - PAVASAS (1987)

\begin{tabular}{|c|l|l|c|c|c|}
\hline Estação & Latitude & Longitude & Prof. (m) & Fundo & Localidade \\
\hline 5 & $02^{\circ} 15^{\prime} 30^{\prime \prime} \mathrm{S}$ & $40^{\circ} 29^{\prime} 18^{\prime}$ & 45 & $\mathrm{~A}$ & $\mathrm{CE}$ \\
\hline 23 & $01^{\circ} 37^{\prime} 00^{\prime} \mathrm{N}$ & $47^{\circ} 55^{\prime} 00^{\prime}$ & 21 & $\mathrm{~A}$ & PA \\
\hline
\end{tabular}

\section{Pesca Norte I (1968)}

\begin{tabular}{|l|c|c|c|c|c|}
\hline \multicolumn{1}{|c|}{ Estação } & Latitude & Longitude & Prof.(m). & Fundo & Localidade \\
\hline Drag.II & $04^{\circ} 27^{\prime} 0^{\prime \prime} \mathrm{N}$ & $49^{\circ} 59^{\prime} 0^{\prime \prime} \mathrm{W}$ & 116 & $\mathrm{~A} / \mathrm{B}$ & $\mathrm{AP}$ \\
\hline Drag.III & $04^{\circ} 43^{\prime} 0^{\prime \prime} \mathrm{N}$ & $50^{\circ} 28^{\prime} 0^{\prime \prime} \mathrm{W}$ & 88 & $\mathrm{~A}$ & $\mathrm{AP}$ \\
\hline
\end{tabular}


Pesquisador IV (1973)

\begin{tabular}{|l|c|c|c|c|c|}
\hline \multicolumn{1}{|c|}{ Estação } & Latitude & Longitude & Prof. (m) & Fundo & Localidade \\
\hline 44 & $01^{\circ} 33^{\prime} 0^{\prime \prime} \mathrm{S}$ & $44^{\circ} 01^{\prime} 0^{\prime \prime} \mathrm{W}$ & 17,0 & $\mathrm{~A}$ & MA \\
\hline $53-\mathrm{B}$ & $00^{\circ} 41^{\prime} 0^{\prime} \mathrm{S}$ & $44^{\circ} 22^{\prime} 0^{\prime \prime} \mathrm{W}$ & 32,5 & $\mathrm{~B}$ & MA \\
\hline
\end{tabular}

Pernambuco (1968 - 1969)

\begin{tabular}{|l|c|c|c|c|c|}
\hline \multicolumn{1}{|c|}{ Estação } & Latitude & Longitude & Prof. (m) & Fundo & Localidade \\
\hline 06 & $08^{\circ} 40^{\prime} 00^{\prime} \mathrm{S}$ & $35^{\circ} 00^{\prime} 20^{\prime \prime}$ & 19 & $\mathrm{~A}$ & $\mathrm{PE}$ \\
\hline 08 & $08^{\circ} 40^{\prime} 00^{\prime} \mathrm{S}$ & $34^{\circ} 45^{\prime} 7^{\prime}$ & $70-90$ & $\mathrm{AC}$ & $\mathrm{PE}$ \\
\hline $16-\mathrm{A}$ & $08^{\circ} 10^{\prime} 00^{\prime} \mathrm{S}$ & $34^{\circ} 39^{\prime} 0^{\prime}$ & $73-74$ & $\mathrm{AC}$ & $\mathrm{PE}$ \\
\hline $34-\mathrm{A}$ & $07^{\circ} 40^{\prime} 02^{\prime} \mathrm{S}$ & $34^{\circ} 43^{\prime} 02^{\prime}$ & $60-88$ & $\mathrm{~A} / \mathrm{AC}$ & $\mathrm{PE}$ \\
\hline 36 & $07^{\circ} 40^{\prime} 00^{\prime} \mathrm{S}$ & $34^{\circ} 28^{\prime} 07^{\prime}$ & $60-88$ & $\mathrm{AC}$ & $\mathrm{PE}$ \\
\hline $36-\mathrm{A}$ & $07^{\circ} 40^{\prime} 00^{\prime} \mathrm{S}$ & $34^{\circ} 28^{\prime} 7^{\prime}$ & $60-88$ & $\mathrm{AC}$ & $\mathrm{PE}$ \\
\hline
\end{tabular}

Itamaracá (1969)

\begin{tabular}{|l|l|c|c|c|}
\hline \multicolumn{1}{|c|}{ Estação } & \multicolumn{1}{c|}{ Localidade } & Profundidade & Fundo & Localidade \\
\hline 19 & Canal de Santa Cruz & 5,60 & A & PE \\
\hline 35 & Canal de Santa Cruz & 0,35 & A & PE \\
\hline 98 & Canal de Santa Cruz & 1,75 & A & PE \\
\hline 102 & Canal de Santa Cruz & 1,90 & A & PE \\
\hline
\end{tabular}

\section{Recife (1967)}

\begin{tabular}{|c|c|c|c|c|c|}
\hline Estação & Latitude & Longitude & Prof. (m) & Fundo & Localidade \\
\hline 3 & $08^{\circ} 09^{\prime} 3^{\prime \prime}$ & $34^{\circ} 49^{\prime} 3^{\prime \prime}$ & 22,0 & $\mathrm{AC}$ & $\mathrm{PE}$ \\
\hline 20 & $08^{\circ} 13^{\prime} 5^{\prime \prime}$ & 3452’8” & 15,5 & $\mathrm{~A}$ & $\mathrm{PE}$ \\
\hline 27 & $08^{\circ} 18^{\prime} 2^{\prime \prime}$ & $34^{\circ} 51^{\prime} 5^{\prime \prime}$ & 26,0 & $\mathrm{AC}$ & $\mathrm{PE}$ \\
\hline 29 & $08^{\circ} 18^{\prime} 2^{\prime \prime}$ & $34^{\circ} 49^{\prime} 6^{\prime \prime}$ & 30,5 & AC & $\mathrm{PE}$ \\
\hline 38 & $08^{\circ} 21^{\prime} 4^{\prime \prime}$ & $34^{\circ} 53^{\prime} 5^{\prime \prime}$ & 19,0 & AC & $\mathrm{PE}$ \\
\hline 107 & 0759’6” & $34^{\circ} 44^{\prime} 9^{\prime \prime}$ & 24,0 & AC & PE \\
\hline 108 & $08^{\circ} 59^{\prime} 2^{\prime \prime}$ & $34^{\circ} 44^{\prime} 7^{\prime \prime}$ & 29,0 & $\mathrm{AC}$ & $\mathrm{PE}$ \\
\hline 112 & $08^{\circ} 16^{\prime} 0^{\prime \prime}$ & $34^{\circ} 51^{\prime} 7^{\prime \prime}$ & 25,5 & AC & $\mathrm{PE}$ \\
\hline 113 & 08॰14’1” & $34^{\circ} 51^{\prime} 5^{\prime \prime}$ & 24,5 & AC & $\mathrm{PE}$ \\
\hline 142 & $08^{\circ} 19^{\prime} 5^{\prime \prime}$ & $34^{\circ} 50^{\prime} 4^{\prime \prime}$ & 28,0 & $\mathrm{AC}$ & $\mathrm{PE}$ \\
\hline 143 & $08^{\circ} 20^{\prime} 3^{\prime \prime}$ & $34^{\circ} 49^{\prime} 9^{\prime \prime}$ & 29,0 & $\mathrm{AC}$ & $\mathrm{PE}$ \\
\hline 148 & 0752'9”' & 3432'6”' & 46,5 & $\mathrm{AC}$ & $\mathrm{PE}$ \\
\hline 156 & 08॰19’9” & $34^{\circ} 38^{\prime} 8^{\prime \prime}$ & $61-68$ & $\mathrm{AC}$ & $\mathrm{PE}$ \\
\hline
\end{tabular}

Legendas: $\mathrm{A}$ = Areia; $\mathrm{L}=$ Lama; $\mathrm{A} / \mathrm{L}=$ Areia e Lama; $\mathrm{O}=$ Organogênico; $\mathrm{AC}$ = Algas calcárias; $\mathrm{AC} / \mathrm{O}=$ Algas Calcárias e Organogênico; $\mathrm{A} / \mathrm{O}=$ Areia e Organogênico; $\mathrm{L} / \mathrm{O}=$ Lama e Organogênico; L/AC = Lama e Algas Calcárias; B = Biodetítrico;A/AC = Areia e Algas Calcárias. 
Tabela 2. Distribuição Geográfica da Subfamília Drillinae na costa do Brasil, com ênfase à região Norte e Nordeste.

\begin{tabular}{|c|c|c|c|c|c|c|c|c|c|c|c|c|c|c|c|c|c|}
\hline \multirow{2}{*}{ Espécies } & \multicolumn{2}{|c|}{ Norte } & \multicolumn{9}{|c|}{ Nordeste } & \multicolumn{3}{|c|}{ Sudeste } & \multicolumn{3}{|c|}{ Sul } \\
\hline & AP & PA & MA & PI & CE & $\mathrm{RN}$ & PB & $\mathrm{PE}$ & $\mathrm{AL}$ & $\mathrm{SE}$ & BA & ES & RJ & SP & PR & SC & RS \\
\hline D. interpleura & & $\mathrm{x}$ & & & & & & & & & & & & & & & \\
\hline S. lithocolleta & $\mathrm{x}$ & $\mathrm{x}$ & & & & & & & & & & & & & & & \\
\hline D. comatotropis & & $\mathrm{x}$ & & & & & & & & & & & & & & $*$ & * \\
\hline C. gibbosa & $\mathrm{x}^{*}$ & & $\mathrm{x}$ & & & & & & & & & & & & & & \\
\hline C. paria & $*$ & $\mathrm{x}$ & $*$ & & & & & & & & & $*$ & & & & & \\
\hline C.albicoma & & $\mathrm{x}$ & & $\mathrm{x}$ & & & & & & & $*$ & & $*$ & & & & \\
\hline C. minor & $\mathrm{x}$ & $\mathrm{x}^{*}$ & $\mathrm{x}$ & & $\mathrm{x}$ & $\mathrm{x}$ & & $\mathrm{x}$ & & & & & & & & & \\
\hline S. coccinata & $\mathrm{x}$ & & $\mathrm{x}$ & & & & & $\mathrm{x}$ & & & $*$ & & & & & & \\
\hline S. lissotropis & & & & & & & & $\mathrm{x}$ & & & & & $*$ & & & & \\
\hline S. carolinae & $\mathrm{x}$ & & & & & & & & & & & & & & & & * \\
\hline S. tantula & $*$ & $\mathrm{x}$ & & & $\mathrm{x}$ & $\mathrm{x}$ & & & & & & & & & & & \\
\hline S. woodringi & $\mathrm{x}^{*}$ & & $\mathrm{x}$ & & & & & & & & & & & & & & \\
\hline L. cookei & $*$ & $\mathrm{x}$ & $\mathrm{x}$ & & & & & & & & & & & & & & \\
\hline L. splendida & $\mathrm{x}^{*}$ & $x^{*}$ & $\mathrm{x}$ & & $\mathrm{x}$ & $\mathrm{x}$ & & & & & & & & & & & \\
\hline F. halidorema & $\mathrm{x}^{*}$ & & & & & & & $\mathrm{x}$ & & & $*$ & & & & & & \\
\hline C. thea & & & & $\mathrm{x}$ & & & & $\mathrm{x}$ & & & $*$ & $*$ & & & & & \\
\hline C. perryae & $\mathrm{x}^{*}$ & $\mathrm{x}$ & $\mathrm{x}$ & & & $\mathrm{x}$ & & $\mathrm{x}$ & & & & & & & $*$ & & \\
\hline N. cydia & $\mathrm{x}$ & $\mathrm{x}$ & $\mathrm{x}$ & & $\mathrm{x}^{*}$ & $\mathrm{x}^{*}$ & & $\mathrm{x}$ & $*$ & & & & & & & & \\
\hline
\end{tabular}




\section{REFERÊNCIAS BIBLIOGRÁFICAS}

ABBOTT, R. T. The Marine Mollusks of Grand Cayman Is. B.W.I. Monogr. Acad. Nat, Sci, Phil., 11:7 - 138, S pl. 7 text Figura 1958.

ABBOTT, R. T. American Seashells: The marine Mollusca Of the Atlantic and Pacific Coast of North. America. 2.ed. New York. Van Nostrand Reinhold, 1974. 663 p.

ABBOTT, R. T; DANCE, S. P. Compendium of seashells. New York: E.P. Dutton, 1982. 410 p. ALTENA, C. O. VAN R. The marine Mollusca of Suriname (Dutch Guiana) Holocene and Recent-Part III. Gastropoda and Cephalopoda. Zoolog. Verhandel., Leiden, n. 139, p. 1-104, 1975.

BARROS, J. C. N. Estudo dos componentes bióticos da margem Continental brasileira. I Micromoluscos dragados durante a Comissão “Canopus”, entre 1965 e 1966. B. Mus. Malacol., Recife, v. 2, p. 57-84, 1994.

BARROS, J. C. N. Moluscos poucos conhecidos no Nordeste do Brasil, novos registros para o Atlântico Sul. B. Mus. Malacol., Recife, v. 2, p. 85-117, 1994.

BARTSCH, P. New mollusks of the family Turritidae. Reports on The Colections by the first Jonhson - Smithsonian Miscellaneous Collections, Washington, v. 91, n. 2, p. 1-29, 1934.

BAYER, F.; VOSS, G. Studies in Tropical American Mollusks. Univ. Miami, 236 pp., illustr.

CARCELLES, A. Catálogo de los moluscos marinos de puerto Quequén. Revista del Museo de la Plata. Zoologia, La plata, t.3, n.23, p. 233-309, ago. 1944.

CASTRO, B. M. \& MIRANDA, L. B. Physical Oceanography of the Western atlantic Continental Shelf located between $4^{\circ} \mathrm{N}$ and $34^{\circ}$ S. The Sea, V. 11, 1998, p. 209-251.

CASTELlANOS, Z. A. de. Micromoluscos poco conocidos del sul Argentino - Chileno. Neotropica, La Plata, v. 25, n. 74, p. 133-140. dez./1979.

CERNOHORSKY, W. O. Comments on the Authorahip of some Subfamilial Names in the Turridae. The Veliger, 15(2):127-128. 1972.

COUTINHO, P. N., Morais, J. O. "Distribución de los sedimentos en La plataforma continental norte y nordeste del Brasil”. Arq. Ciênc. Mar., v. 10, n. 1, p. 79-90. 1970.

DALL, W. H. Descriptions of new species of molluks of the family Turritidae from the west coas of America and Adjacent Regions. Proc. U. S. Nat. Mus., v. 56 (2288). 1920.

EKDALE, Allan A. Marine mollusks from shallow - water environments (0 to 60 meters) off the Northeast Yucatan Coast, Mexico. Bull. Mar. Sci. V. 24, n. 3, p. 638-668. 1974.

FIGUEIRAS, A. \& SICARDI, O. Catálogo de los Moluscos Marinos del Uruguay (x) (Section II). Com. Soc. Malac. Urug., p. 179 - 277, pl. 3-6.

HYMAN. L. H. The Invertebrates Mollusca. v 1. McGraw-Hill. New York, 1967. 
KEEN, A. M. Sea Shells of tropical west America: marine Mollusca from Baja California to Peru. 2.ed. California: Stanford University Press, 1971, p. 1064.

KEMPF, M., COUTINHO, P. N., MORAIS, J.O. Plataforma Continental do Norte e Nordeste do Brasil: nota preliminar sobre a natureza do fundo. Trab. Ocean. Univ. Fed._PE, Recife, v. 9/11, p. 9-26, 1970.

KEMPF, M. A plataforma continental de Pernambuco, Brasil: nota preliminar sobre a natureza do fundo. Trab. Ocean. Univ. Fed. PE, Recife, v. 9/11, n.11, p. 111-124, 1970.

KEMPF, M., MATTHEWS, H.R. Marine mollusks from North and Northeast of Brazil. IPreliminary list. Arq. Est. Biol. Mar. Univ. Fed. do Ceará, Fortaleza, v. 8, n. 1, p. 87-94, 1968. LINDNER, G. Moluscos y Caracoles de los Mares del Mundo. Ediciones Ômega S.A., Barcelona, 255 p. 64 lâminas, 1975.

LYONS, W. C. New Turritidae (Gastropoda: Toxoglossa) from south Florida and the eastern Gulf of Mexico. The Nautilus, 86 (1): 3-7. 1972.

MAES, V. O., "Observations on the systematics and biology of a Turridae Gastropod assemblage in the British Virgin Islands.” Bull Mar. Sci, 33 (2): 305-335, 1983.

MAGALHÃES, J.; MEZZALIRA, S. Moluscos fósseis do Brasil. Rio de Janeiro: Departamento de Imprensa Nacional, 1953. 283p

MATTHEWS, H. R., KEMPF, M. Terceira contribuição ao inventário dos moluscos marinhos do Nordeste brasileiro. Arq. Ciên. Mar., Fortaleza, v. 14, n.1, p. 27-35, 1969.

MATTHEWS, H. R.; KEMPF, M. Moluscos marinhos do Norte e Nordeste do Brasil. II-Moluscos do Arquipélago de Fernando de Noronha. Arq. Ciênc. Mar., Fortaleza, v. 10, n. 1, p. 1-53, 1970.

MATTHEWS, H. R.; KEMPF, M. Quarta contribuição ao inventário dos moluscos marinhos do Nordeste brasileiro. Arq. Ciên. Mar., Fortaleza, v. 14, n. 1, p. 47-56, 1974.

MATTHEWS, H. R; RIOS, E. C. Primeira contribuição ao inventário dos moluscos marinhos do Nordeste brasileiro. Arq. Est. Biol. Mar. Univ. Fed. do Ceará, Fortaleza, v. 7, n.1, p. 67-77, 1967.

MAURY, C. J. Fósseis terciários do Brasil, com descrição de novas formas cretáceas. Rio de Janeiro: Serviço Mineralógico do Brasil, 1924. 665 p. (Monografia, 4).

MELLO, R. de L.S. Fauna malacológica do mesolitoral da Ilha de Itamaracá, Pernambuco. Anais da Univ. Fed. Rur. de Pernambuco, Recife, v. 4, p. 157-166, 1979.

MELLO, R. de L.S. Fauna malacológica do mesolitoral norte de Pernambuco, Olinda. Anais da Univ. Fed. Rur. de Pernambuco, Recife, v. 6, p. 127-140, 1981.

MELLO, R. de L. S. BARROS, J. C. N. de. Microgastrópodes do litoral do Estado de Pernambuco não registrados para o Brasil. Siratus, São Paulo, v. 2, n. 11, p. 13-17, jul. /ago., 1991.

MERLANO, J. M. D; HEGEDUS, M. P. Moluscos del Caribe Colombiano. Colciencias \& Fundación Natura. Ivemar. v. 1 Colombia, 1997. 
MOORE, R. C. Treatise on invertebrate paleontology. Kansas: Geological Society of America, University of Kansas, Part “N”, v. 2, 1969. 952 p.

MORRETES, F. L. Catalogo dos moluscos do Brasil. Arq. Mus. Paranaense, Curitiba, v. 7, n. 1, p. 3-216, 1949.

OLSSON, A.; McGINTY, T. L. Recent marine molluska from the Caribbean coast of Panamá with descriptions of some new genera and species. Bulletin of American_Paleontology, Ithaca, v. 39 n. 177, p. 31-52, 1958.

PETUCH, E. J. New Caribbean molluscan fauna. Virginia: The Coastal education and Research Foundation, 1987. 154 p.

PILSBRY, H. A; LOWE, H. N. West Mexican and Central American Mollusks collected by H. N. Lowe. Proc. Acad. Nat. Sci. Phil., v. 84, 1929. 14599.

POWELL, A W. B. The new Zealand Recent and Fossil Mollusca of the family Turridae. Bull Auc. Inst. Mus. ${ }^{0}$ 2. 1942.

POWELL, A W. B. The Molluscan Families Speightidae and Turridae. Bulletin of the_Auckland Institute and Museum, 1966, 5:1-184, 23 plates.

RIOS, E. C. Coastal Brazilian Seashells. Rio Grande: Museu Oceanográfico do Rio Grande, 1970. $255 \mathrm{p}$.

RIOS, E. C. Brazilian Marine Mollusks Iconography. Rio Grande: Museu Oceanográfico da Fundação Universidade do Rio Grande, 1975. 331 p.

RIOS, E. C. Seashells of Brazil. Rio Grande: Fundação cidade do Rio Grande, Fundação Universidade do Rio Grande, 1985. 328 p.

RIOS, E. C. Seashells of Brazil. Rio Grande: Fundação cidade do Rio Grande, Fundação Universidade do Rio Grande, 1994. 368 p., 113 pl.

SANTOS, W. S. \& TENÓRIO, D. O. Gastrópodos Turridae de la Plataforma Continental Norte de Brasil. In: Congresso latino-americano de malacologia, VI reunión nacional de malacologia y conquiliologia, 1997, IVEMAR Ensenada, Baja California, México: Resumos... p. 205-206.

TABB, D.; MANNING, R. B. A checklist of the flora and fauna of northern Florida Bay and adjacent brackish waters of the Florida mainland collected during the period july, 1957through September, 1960. Bull. Mar. Sci., 11 (4): p. 552-649. 1961.

VOKES, H. E., VOKES, E. H. Distribution of shallow-water marine Mollusca Yucatan Peninsula, México. New Orleans: Tulane University, 1983. VIII + 183 p. (Mesoamerican Ecology Institute; Monograph 1, Middle American Research Institute. Publication 54).

WARMKE, G. ABBOTT, R. T. Caribbean Seashells: a guide to the marine mollusks of Puerto Rico and other West Indian Islands, Bermuda and the lower Florida Key. Narbeth: Livingstone Publish, 1962. 348 p. 
WATSON, R. B. Report on the Scientific Results of the Voyage of the "Challenger” during_the years of 1873-1976; v. 15, Part. 42, 756 p., 53 pl.

WENZ, W. Handbuch der Paläozoologie. v. 6, 1639 pp., Berlin. 1938/44 
